\title{
3-Fluoro-4-hydroxyprolines: Synthesis, Conformational Analysis, and Stereoselective Recognition by the VHL E3 Ubiquitin Ligase for Targeted Protein Degradation
}

\author{
Andrea Testa, ${ }^{\dagger}$ Xavier Lucas, ${ }^{\dagger}$ Guilherme V. Castro, $^{\dagger}$ Kwok-Ho Chan, $^{\dagger}$ Jane E. Wright,
} Andrew C. Runcie, ${ }^{\dagger}$ Morgan S. Gadd, ${ }^{\dagger, \perp}$ William T. A. Harrison, ${ }^{\ddagger}$ Eun-Jung Ko, ${ }^{\S}$ Daniel Fletcher, ${ }^{\S}$ and Alessio Ciulli ${ }^{*} \dagger$ (C)

${ }^{\dagger}$ Division of Biological Chemistry and Drug Discovery, School of Life Sciences, University of Dundee, James Black Centre, Dow Street, Dundee DD1 5EH, Scotland, U.K.

${ }^{\ddagger}$ Department of Chemistry, University of Aberdeen, Meston Walk, Aberdeen AB24 3UE, Scotland, U.K.

${ }^{\S}$ Drug Discovery Unit, Division of Biological Chemistry and Drug Discovery, School of Life Sciences, University of Dundee, James Black Centre, Dow Street, Dundee DD1 5EH, Scotland, U.K.

\section{Supporting Information}

ABSTRACT: Hydroxylation and fluorination of proline alters the pyrrolidine ring pucker and the trans:cis amide bond ratio in a stereochemistry-dependent fashion, affecting molecular recognition of proline-containing molecules by biological systems. While hydroxyprolines and fluoroprolines are common motifs in medicinal and biological chemistry, the synthesis and molecular properties of prolines containing both modifications, i.e., fluoro-hydroxyprolines, have not been described. Here we present a practical and facile synthesis of all four diastereoisomers of 3-fluoro-4-hydroxyprolines (F-

Hyps), starting from readily available 4-oxo-L-proline derivatives. Small-molecule X-ray crystallography, NMR spectroscopy, and quantum mechanical calculations are consistent with fluorination at $\mathrm{C}^{3}$ having negligible effects on the hydrogen bond donor capacity of the $\mathrm{C}^{4}$ hydroxyl, but inverting the natural preference of Hyp from $\mathrm{C}^{4}$-exo to $\mathrm{C}^{4}$-endo pucker. In spite of this, $\mathrm{F}$-Hyps still bind to the von Hippel-Lindau (VHL) E3 ligase, which naturally recognizes $\mathrm{C}^{4}$-exo Hyp in a stereoselective fashion. Cocrystal structures and electrostatic potential calculations support and rationalize the observed preferential recognition for $(3 R, 4 S)$-F-Hyp over the corresponding $(3 S, 4 S)$ epimer by VHL. We show that $(3 R, 4 S)$-F-Hyp provides bioisosteric Hyp substitution in both hypoxia-inducible factor 1 alpha (HIF-1 $\alpha$ ) substrate peptides and peptidomimetic ligands that form part of PROTAC (proteolysis targeting chimera) conjugates for targeted protein degradation. Despite a weakened affinity, Hyp substitution with $(3 S, 4 S)$-F-Hyp within the PROTAC MZ1 led to Brd4-selective cellular degradation at concentrations $>100$ fold lower than the binary $K_{\mathrm{d}}$ for VHL. We anticipate that the disclosed chemistry of 3-fluoro-4-hydroxyprolines and their application as VHL ligands for targeted protein degradation will be of wide interest to medicinal organic chemists, chemical biologists, and drug discoverers alike.

\section{INTRODUCTION}

(2S,4R)-4-Hydroxyproline (Hyp) is a nonessential amino acid, prevalently found in collagen and produced by the most common, irreversible, posttranslational modification in animals: proline hydroxylation. ${ }^{1-3}$ Introduction of the hydroxyl group on the five-membered ring of proline at the $4 R$ position affects the pyrrolidine ring puckering, shifting the $\mathrm{C}^{4}$-endo pucker preference of proline to the $\mathrm{C}^{4}$-exo pucker of Hyp. ${ }^{4-6}$ The $\mathrm{C}^{4}$-exo conformer in Hyp is stabilized by the well-known gauche effect (Chart 1A). ${ }^{7}$ This particular conformer allows a gauche arrangement between the two electronegative substituents of two vicinal carbons, i.e., the prolyl amide group and the hydroxyl group (dihedral angle $\mathrm{N}-\mathrm{C}^{5}-\mathrm{C}^{4}-\mathrm{O}$ of approximately 60 degrees). ${ }^{4,5,8}$ Notably, the $C^{4}$-exo pucker conformation places the carbonyl of the $i$ amino acid in the correct position to interact with the Hyp carbonyl $(i+1)$, enabling an $\mathrm{n} \rightarrow \pi^{*}$ interaction that in turn stabilizes the trans amide bond in Hyp-containing peptides and proteins. ${ }^{4,5}$ As a result of the gauche effect, conversely, the diastereoisomer $(2 S, 4 S)$-4-hydroxyproline (hyp) adopts a $\mathrm{C}^{4}$-endo pucker conformation, which reduces the $\mathrm{n} \rightarrow \pi^{*}$ interaction and leads to a lower trans:cis amide ratio. ${ }^{9}$ Following similar considerations, the puckering system for the less common 3hydroxyprolines can be explained and predicted. ${ }^{10,11}$

Received: June 8, 2018

Published: June 27, 2018 
Chart 1. Chemical Structures of Hydroxyl- and Fluoroprolines: (A) Conformational Preferences of 4-Substituted Hydroxyprolines and Fluoroprolines; (B) Examples of 4Fluoro- and 4-Hydroxyprolines in Medicinal Chemistry; (C) 3-Fluoro-4-hydroxyprolines (F-Hyps), the Object of This Study

A

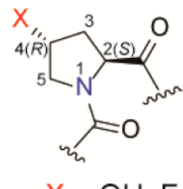

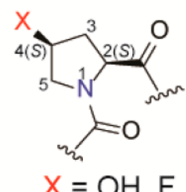

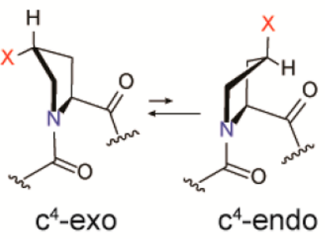

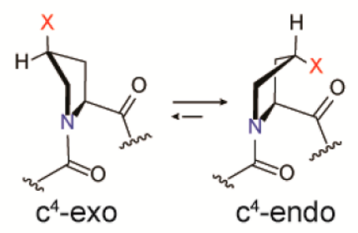

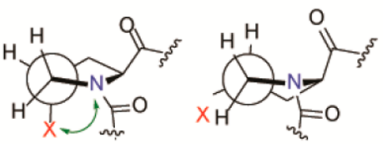
gauche effect

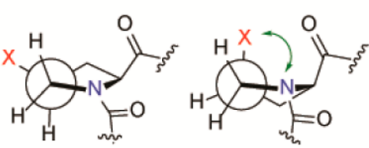

gauche effect

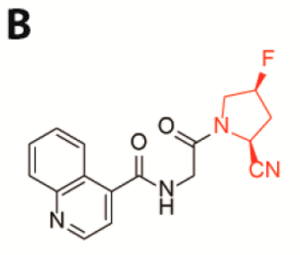

FAP inhibitor
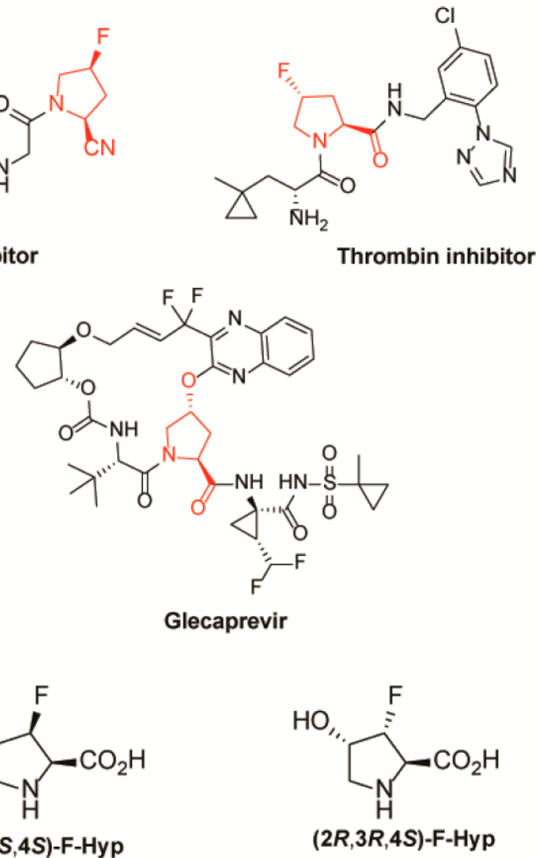

$(2 R, 3 S, 4 S)-F-H y p$<smiles>O=C(O)[C@@H]1NC[C@@H](O)[C@@H]1F</smiles>
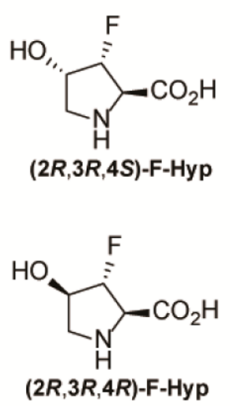

The realization that the stereochemistry of electronegative atoms on proline rings can greatly affect the conformation of the pucker and the trans:cis amide bond ratio has prompted the design and synthesis of a diverse array of unnatural proline derivatives. ${ }^{12}$ Among these, monofluorinated ${ }^{13,14}$ and trifluoromethyl prolines ${ }^{15}$ have been extensively studied. Fluorination

at $\mathrm{C}^{4}$ or $\mathrm{C}^{3}$ causes stabilization of the $\mathrm{C}^{4}$-endo/ $\mathrm{C}^{4}$-exo ring pucker in a similar fashion to hydroxylation, according to the same gauche effect. ${ }^{13,14}$ To this end, 4-fluoro and 3-fluoro prolines have been incorporated in proteins such as collagen, ${ }^{16}$ ubiquitin, ${ }^{17}$ and GFP, ${ }^{18}$ used to probe prolyl isomerase enzyme activity by $\mathrm{NMR}^{19}$ and used as PET probes. ${ }^{20}$ Beyond proteins, fluorinated prolines have also found applications as building blocks for medicinal chemistry, ${ }^{21}$ reflecting the wide interest in fluorination as a strategy to finely tune conformational and physicochemical properties of biologically active small molecules and peptides. ${ }^{2-25}$ For instance, the incorporation of $(4 S)$ - or (4R)-4-fluoroprolines into inhibitors of fibroblast activation protein (FAP) ${ }^{26}$ and thrombin ${ }^{27}$ (Chart 1B) stabilizes a single conformational pucker of the pyrrolidine ring (the $\mathrm{C}^{4}$-endo in the case of FAP inhibitor and the $\mathrm{C}^{4}$-exo for thrombin inhibitor), which results in improved potency compared to the unsubstituted proline analogues. More recently, mono- and difluorinated prolines were discovered to enhance key $\mathrm{CH} / \pi$ interactions in peptide-protein complexes. $^{28}$ Like fluorinated prolines, hydroxyprolines are common building blocks in medicinal chemistry: the Hyp core can be found in the structure of recently FDA approved inhibitors of the NS3-4A serine protease such as glecaprevir ${ }^{29}$ (Chart 1B). Curiously, despite the variety of fluorinated and hydroxylated proline derivatives reported in the literature, the simultaneous presence of these two modifications within the same pyrrolidine ring is unprecedented. Introduction of fluorine substituents can modulate the electronic and conformational properties of small molecules, thus impacting protein-ligand and protein-protein binding affinities, as well as metabolism and cell permeability. ${ }^{21}$ We therefore became interested in exploring the synthesis and stereoelectronic properties of fluorinated hydroxyprolines, which we call FHyps (Chart 1C). We hypothesized that the addition of the highly electronegative $\mathrm{F}$ atom adjacent to the hydroxyl group on the pyrrolidine ring could significantly alter the puckering preference of the ring and affect the cis:trans amide ratio. Moreover, it was anticipated that fluorination of hydroxyproline would fine-tune the acidity, nucleophilicity, and hydrogenbond properties of the hydroxyl group, depending on the stereochemistry of the fluorine atom. To this end, previous reports have studied the influence of fluorine on the $-\mathrm{OH}$ group acidity in the context of 2-fluorocyclohexanols and have shown that fluorination can lead to a reduction of alcohol $\mathrm{H}$ bond acidity as a result of intramolecular $\mathrm{F} \cdot \mathrm{HO}$ interactions. $^{30}$

Beyond its structural role in collagen, Hyp has a central role in oxygen sensing, a biological process of fundamental physiological and therapeutic relevance. ${ }^{31}$ Specifically, hydroxylation of the hypoxia-inducible factor 1 alpha (HIF-1 $\alpha$ ) subunits at two conserved proline residues (Pro402 and Pro564 in HIF-1 $\alpha$ ), which is catalyzed primarily by the prolyl hydroxylase enzyme PHD2 (also known as EGLN1), ${ }^{32,33}$ triggers the binding of HIF- $1 \alpha$ to the von Hippel-Lindau (VHL) Cullin RING E3 ubiquitin ligase (Figure 1A). This recognition event leads to HIF- $1 \alpha$ polyubiquitylation by the VHL ligase complex and subsequent proteasomal degradation under normal oxygen levels, preventing the transcription of hypoxia response genes. ${ }^{34-36}$ Work from our laboratory and others leveraged the highly specific molecular recognition of Hyp by the VHL E3 ubiquitin ligase (Figure 1B) to design and develop potent small-molecule VHL ligands. ${ }^{37-41}$ In one application, VHL ligands work in their own right as disruptors 
A

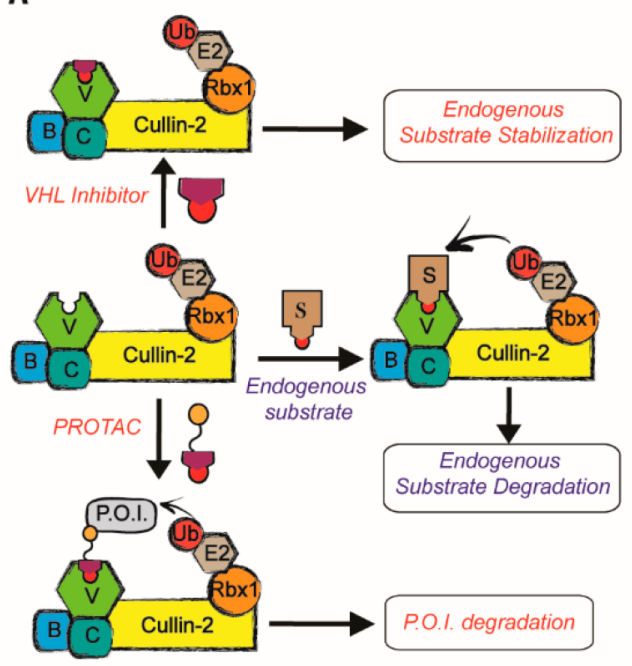

B

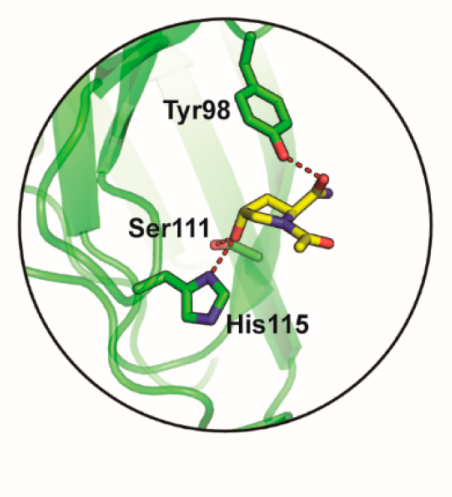

C
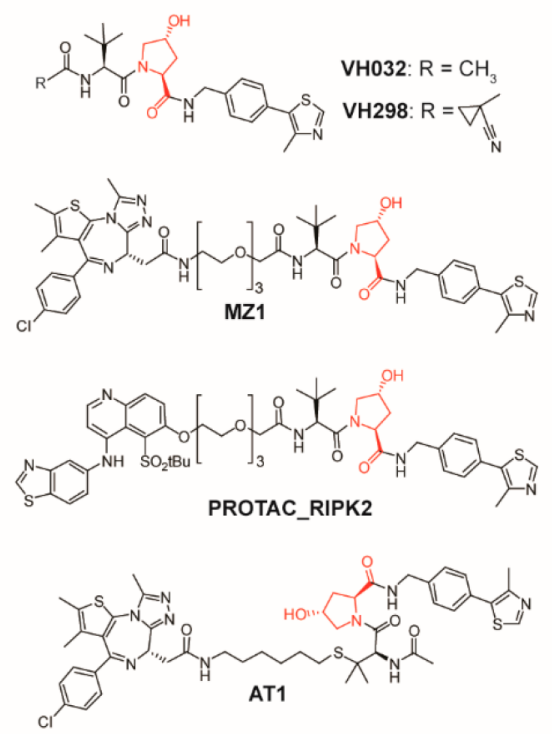

Figure 1. von Hippel-Lindau E3 ligase recognition of Hyp for VHL ligands and PROTACs. (A) Schematic representation of the VHL E3 ligase recognition and ubiquitylation of the endogenous substrate, inhibition of the catalytic activity of VHL by blocking the substrate recognition site, and PROTAC-induced targeted protein ubiquitylation by VHL hijacking. (B) Hyp-binding site with key polar interactions between VHL and Hyp in a $\mathrm{C}^{4}$-exo, trans amide conformation. (C) Examples of VHL inhibitors and VHL-based PROTACs built around the essential Hyp core.

of the VHL-HIF protein-protein interaction to block the ubiquitination of HIF- $1 \alpha$ downstream of HIF hydroxylation. This blockade leads to HIF- $1 \alpha$ stabilization in cells, triggering a hypoxic response under otherwise normoxic conditions (Figure 1A). ${ }^{39-41}$ In a distinct application, VHL ligands provide suitable drug-like starting points for conjugation into bivalent degrader molecules, also known as proteolysistargeting chimeras (PROTACs), which hijack the VHL E3 ligase activity to trigger ubiquitination and degradation of specific target proteins. ${ }^{42-44}$ Many potent and selective Hypbased PROTACs have been recently reported against a wide range of target proteins, including Brd4, ${ }^{45,46} \mathrm{RIPK} 2,{ }^{47} \mathrm{c}$-Abl kinase, ${ }^{48}$ VHL itself, ${ }^{49}$ TBK1, ${ }^{50}$ and TRIM $24^{51}$ among others. A notable example among the first to be disclosed is MZ1 (Figure 1C), a potent and selective degrader for the bromodomain and extra-terminal (BET) protein Brd4 with profound antiproliferative activity in acute myeloid leukemia cells. $^{45,46}$ Our crystal structure of MZ1 bound in a ternary complex with VHL, elongin $\mathrm{B}$, and elongin $\mathrm{C}$ (hereafter called $\mathrm{VBC}$ ), and the bromodomain of the target protein Brd4 revealed a structural basis for the cooperative ternary complex recognition that underpins the mode of action of the degrader molecule. $^{52}$ The design of bivalent degrader molecules is seeing increasing interest for drug development, due to their catalytic rather than occupancy-based mode of action and an extended duration of action at low concentrations in substoichiometric fashion. ${ }^{53}$ All current VHL-targeting degraders contain Hyp as the core building block. It would therefore be of interest and potentially beneficial to replace Hyp with novel scaffolds, for example by introducing substitutions that might fine-tune the molecular recognition and pharmacokinetic properties of the final compounds.

Here we describe the synthesis of novel F-Hyps. We developed synthetic routes that allow efficient and robust synthesis for all four possible diastereoisomers and extensively studied their conformational and stereoelectronic properties using NMR spectroscopy, X-ray crystallography, and computa- tional approaches. The simultaneous presence of $\mathrm{F}$ and $\mathrm{OH}$ on the proline ring was found to affect the conformational and electronic properties of the amino acid, which could be rationalized by means of small-molecule crystal structures and quantum mechanics calculations. Finally, to provide a proof-ofconcept for the application of F-Hyps as building blocks to probe biology, we systematically incorporated F-Hyps in place of Hyp into a diverse set of HIF- $1 \alpha$ peptides, VHL ligands, and VHL-targeting PROTACs and investigated the effect of fluorination of Hyp on VHL binding. We found that VHL exhibits a highly stereoselective recognition of the $(3 R, 4 S)-3$ fluoro-4-hydroxyproline over the $(3 S, 4 S)$ epimer. We show that $(3 R, 4 S)$-3-fluoro-4-hydroxyproline incorporation achieved ligands and PROTACs with affinities and cellular activities comparable to those of the parent Hyp-containing compounds, while incorporation of the $(3 S, 4 S)$ epimer led to Brd4-selective degradation at nanomolar concentration in spite of a loss of $\sim 20$-fold binding affinity to VHL.

\section{RESULTS AND DISCUSSION}

2.1. Chemistry. To prepare the desired 3-fluoro-4-hydroxy prolines, we envisaged a synthetic strategy based on electrophilic fluorination of an enolate or enolate equivalent of $\mathrm{N}$ Boc-4-oxo-L-proline benzyl ester $\mathbf{1}$, which is known to be regioselectively enolized at the $\mathrm{C}^{3}$ under kinetic conditions. ${ }^{54}$ In a first set of experiments, the lithium, sodium, and potassium enolate of $\mathbf{1}$, generated by treatment of ketone $\mathbf{1}$ with the corresponding metal hexamethyldisylazides at $-78^{\circ} \mathrm{C}$ in tetrahydrofuran (THF), were reacted with $\mathrm{N}$-fluorobenzenesulfonimide at $-78{ }^{\circ} \mathrm{C}$, and the reaction mixtures were allowed to slowly warm to room temperature overnight. In all cases, no fluorinated ketone was detected by ${ }^{19} \mathrm{~F}$ NMR, and complex reaction mixtures were obtained. We next attempted to prepare the trimethylsilyl enol ether 2 (Scheme 1) by quenching the lithium enolate of $\mathbf{1}$ with trimethylsilyl chloride, as described previously. ${ }^{54}$ Silyl enol ether 2 was isolated by pentane extraction and, after solvent removal, directly reacted 


\section{Scheme 1. Synthesis of F-Hyps N-Protected Amino Acids}
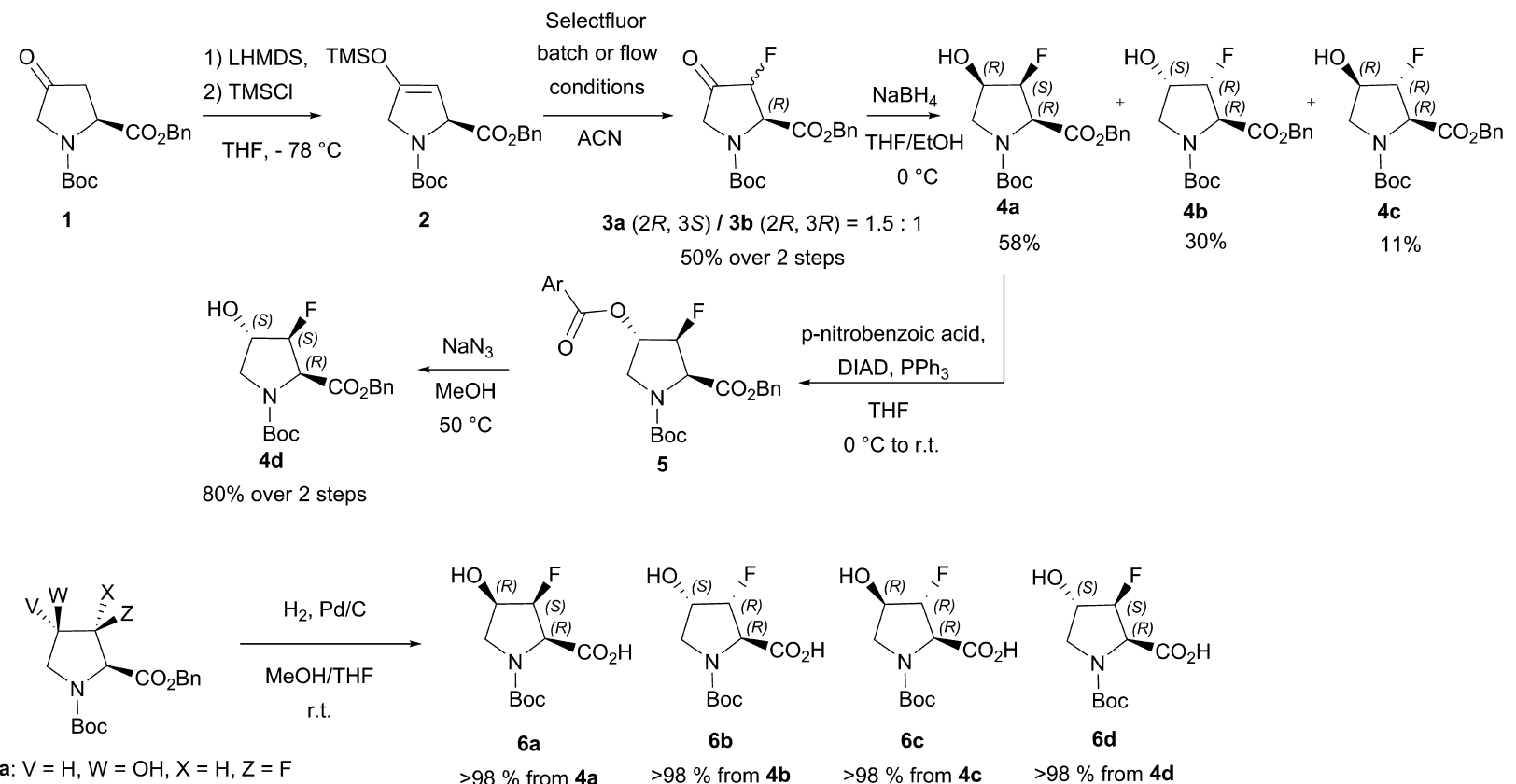

4a: $V=\mathrm{H}, \mathrm{W}=\mathrm{OH}, X=\mathrm{H}, \mathrm{Z}=\mathrm{F}$

$>98 \%$ from $4 a$

$>98 \%$ from $\mathbf{4 b}$

$>98 \%$ from $4 c$

$>98 \%$ from $4 d$

$\mathrm{de}: \mathrm{V}=\mathrm{OH}$

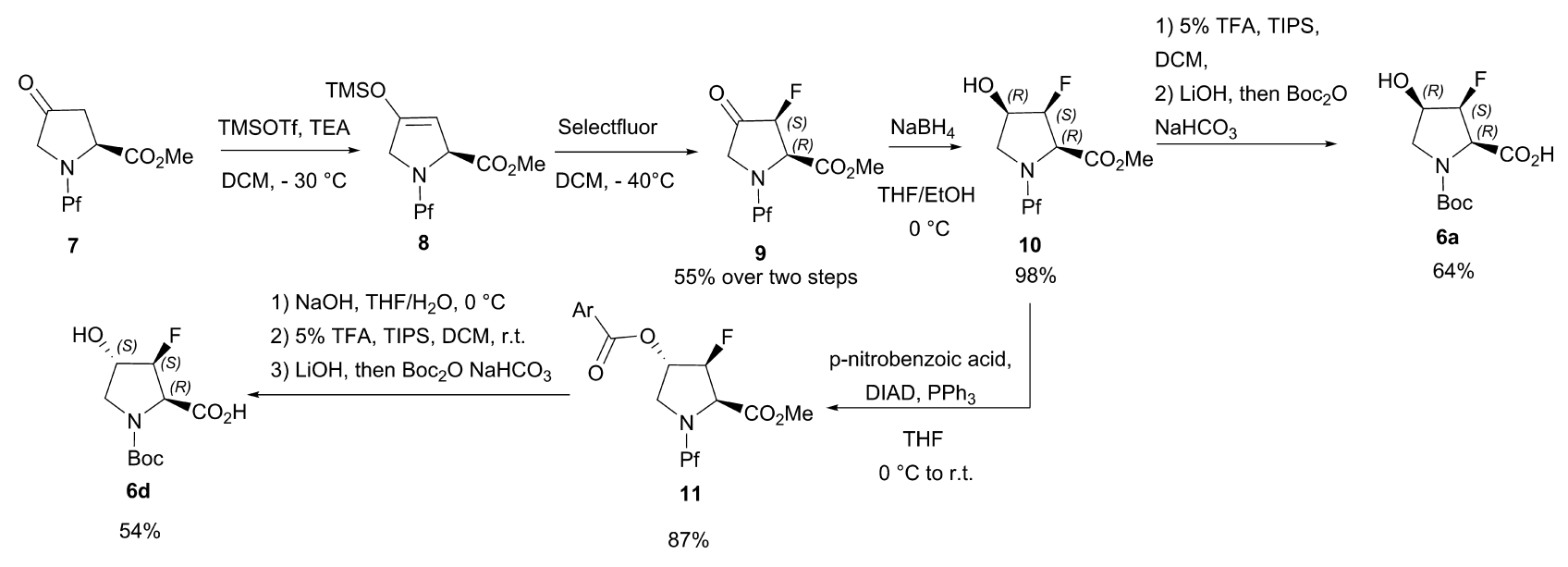

with Selectfluor in acetonitrile at $-30^{\circ} \mathrm{C}$. The reaction mixture was allowed to slowly warm to room temperature overnight, and we were pleased to observe a set of ${ }^{19} \mathrm{~F}$ NMR signals compatible with a diastereoisomeric mixture of fluorinated ketones $3 \mathbf{a}, \mathbf{b}$ in a $\sim 1.5: 1$ ratio and $50 \%$ overall isolated yield. However, variability of yield and diastereoisomeric ratio was observed when scaling up this reaction, with considerable reduction of yield when the fluorination was performed in gram scale. As a reliable fluorination protocol was highly desirable, a flow chemistry approach was considered. No examples of fluorination of silyl enol ether in flow conditions were found in the literature, except for a closely related $\alpha$ fluorination of activated carbonyl compounds with Selectfluor, reported by the Ley laboratory in 2009. ${ }^{55}$ Under optimized conditions, the silyl enol ether $\mathbf{2}$ and Selectfluor were dissolved in anhydrous acetonitrile ( 0.67 and $0.1 \mathrm{M}$, respectively) and pumped at a rate of $0.77 \mathrm{~mL} / \mathrm{min}$ in a $10 \mathrm{~mL}$ flow reactor (residence time $6.5 \mathrm{~min}$ ) heated at $50{ }^{\circ} \mathrm{C}$. The mixing was provided by a $\mathrm{T}$ piece junction before the coiled reactor. The crude product was treated with a saturated solution of $\mathrm{NH}_{4} \mathrm{Cl}$ and filtered over a short silica column, providing the fluorinated ketones $\mathbf{3 a}, \mathbf{b}$ in a $\sim 1: 1$ ratio and $55 \%$ isolated yield.

Because any attempt to separate the diastereoisomers by column chromatography failed, we decided to subject the diastereoisomeric mixture to sodium borohydride reduction. Three fluorohydrines were isolated, $\mathbf{4 a}$ in $58 \%, \mathbf{4 b}$ in $30 \%$, and $4 \mathrm{c}$ in $11 \%$ yield. Despite being complicated by the well-known conformational isomerism shown by $\mathrm{N}$-Boc prolines, the ${ }^{1} \mathrm{H}$ NMR spectra of $\mathbf{4 a}, \mathbf{4 b}$, and $\mathbf{4 c}$ in $\mathrm{CDCl}_{3}$ showed remarkable differences in the coupling constants between $\mathrm{H}^{2}$ and $\mathrm{H}^{3}$ (see Figure $2 \mathrm{~A}$ for numbering of the proline ring): $J_{\mathrm{H} 2-\mathrm{H} 3}=5.9 \mathrm{~Hz}$ in $\mathbf{4 a}$ and close to zero in $\mathbf{4 b}$ and $\mathbf{4 c}$. This observation suggested that in $4 \mathrm{a}$ the fluorine atom and the carboxylate may be present in a cis conformation, in which the angle between 


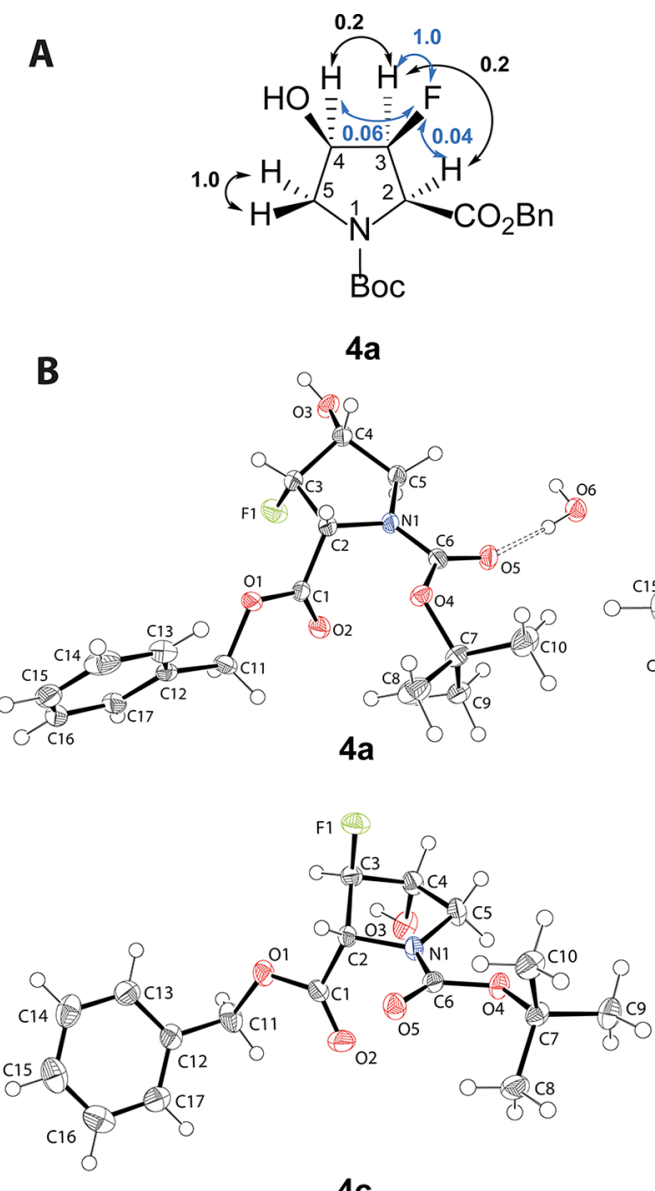

4c

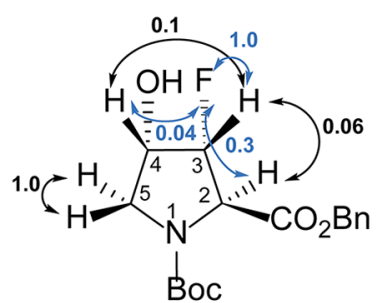

4b

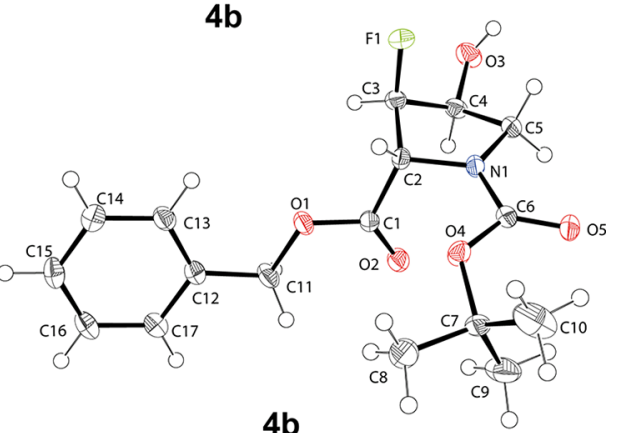

4b

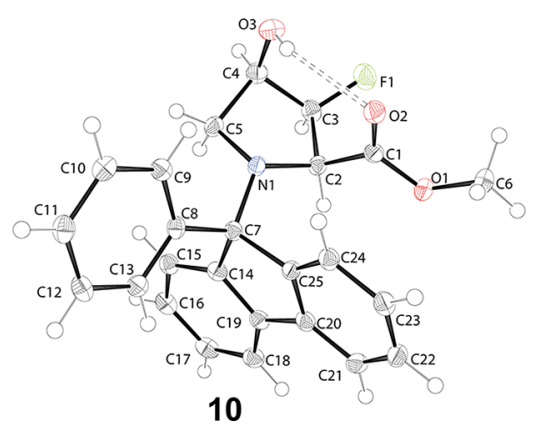

Figure 2. Structural assignment of F-Hyps. (A) Numbering of the F-Hyp ring and stereochemical assignment for 4a,b by NMR (NOESY values of cross-peaks in black, ${ }^{19} \mathrm{~F}-{ }^{1} \mathrm{H}$ HOESY values of cross-peaks in blue). (B) Molecular structure of compounds $4 \mathrm{a}-\mathrm{c}$ and 10 showing $50 \%$ displacement ellipsoids resulting from small-molecule X-ray crystallography.

$\mathrm{H}^{2}$ and $\mathrm{H}^{3}$ is consistent with a relatively large $J_{\mathrm{H} 2-\mathrm{H} 3}$ value. On the other hand, the $J_{\mathrm{H} 2-\mathrm{H} 3}$ value observed for $4 \mathbf{b}$ and $4 \mathbf{c}$ suggests an angle between $\mathrm{H}^{2}$ and $\mathrm{H}^{3}$ around $90^{\circ}$, possible when the fluorine atom and the carboxylate arrange in a trans conformation. The stereochemistry of the main products $4 a$ and $\mathbf{4 b}$ was unequivocally assigned by means of NOESY and ${ }^{19} \mathrm{~F}$-detected ${ }^{19} \mathrm{~F}-{ }^{1} \mathrm{H}$ HOESY NMR experiments (Figure $2 \mathrm{~A}$ ). In the case of $4 a$, the relative intensities of NOESY peaks for $\mathrm{H}^{2}-\mathrm{H}^{3}$ and $\mathrm{H}^{3}-\mathrm{H}^{4}$ were consistent with a cis arrangement of $\mathrm{H}^{2}-\mathrm{H}^{3}-\mathrm{H}^{4}$ (Figure 2A). The relative intensity of the ${ }^{19} \mathrm{~F}-{ }^{1} \mathrm{H}$ HOESY peaks for $\mathrm{H}^{2}-\mathrm{F}$ and $\mathrm{H}^{4}-\mathrm{F}$ were equally low and compatible with a trans arrangement of the $\mathrm{F}$ atom with both $\mathrm{H}^{2}$ and $\mathrm{H}^{4}$. For $\mathbf{4 b}$, a cis arrangement could be deduced only for $\mathrm{H}^{3}-\mathrm{H}^{4}$, as the intensity of the NOESY peak for $\mathrm{H}^{2}-\mathrm{H}^{3}$ was $40 \%$ lower than the one for $\mathrm{H}^{3}-\mathrm{H}^{4}$ (Figure 2A). Consistently, the relative intensity of the ${ }^{19} \mathrm{~F}-{ }^{1} \mathrm{H}$ HOESY peaks for $\mathrm{H}^{2}-\mathrm{F}$ was $87 \%$ higher than the one for $\mathrm{H}^{4}-\mathrm{F}$, confirming a cis arrangement between $\mathrm{H}^{2}-\mathrm{F}$ and a trans relationship between $\mathrm{H}^{4}-\mathrm{F}$ (Figure 2A). These observations reveal that the main products of the reduction, $\mathbf{4 a} \mathbf{a}, \mathbf{b}$, result from a hydride delivery anti to the fluorine atom. This same preference had previously been observed in the reduction of conformationally locked fluorocyclohexanones. ${ }^{30}$

Mitsunobu esterification of $\mathbf{4 a}$ and $\mathbf{4 b}$ with 4 -nitrobenzoic acid was conducted, followed by deprotection by sodium azide in methanol. ${ }^{56}$ This allowed access to the fourth diastereoisomer (4d) when starting from $4 \mathbf{a}$ and to a product identical to $4 c$ when starting from $4 b$. These results confirmed that the minor product of the borohydride reduction, $4 c$, is the epimer at the $\mathrm{C}^{4}$ of $\mathbf{4 b}$. As expected, for the newly synthesized compound 4d, the coupling constant between $\mathrm{H}^{2}$ and $\mathrm{H}^{3}$ (5.2 $\mathrm{Hz}$ ) is very similar to its $\mathrm{C}^{4}$ epimer $4 \mathrm{a}$. The stereochemical assignment of $4 a-c$ was also confirmed by X-ray diffraction of the isolated products (Figure 2B and Supp. Figures 3-5). Interestingly, $\mathbf{4 a}, \mathbf{b}$ crystallized with a cis carbamate configuration (similarly to a previously reported $\mathrm{N}$-Boc proline derivative $^{9}$ ), whereas $4 \mathrm{c}$ crystallized with a trans carbamate configuration. For the $(4 R)$ derivatives $4 \mathrm{a}$ and $4 \mathrm{c}$ no transannular hydrogen bond between the carboxylate and the hydroxyl group was found. Finally, catalytic hydrogenation of the benzyl esters $\mathbf{4 a}-\mathbf{d}$ afforded the Boc-protected amino acids $6 a-d$ in good yield and sufficient purity to be used for further synthetic steps.

With the aim to develop a stereoselective synthesis, and inspired by previous work on the synthesis of kainic acid analogues, ${ }^{57}$ the fluorination step was attempted on the 9phenyl fluorenyl (Pf)-protected silyl enol ether 8, prepared from ketone 7 , trimethylsilyl triflate, and triethylamine in dichloromethane (DCM) at $-40{ }^{\circ} \mathrm{C}$. Treatment of the silyl enol ether 8 with Selectfluor in acetonitrile at $-20{ }^{\circ} \mathrm{C}$ afforded the fluorinated ketone 9 as a sole diastereoisomer in $50 \%$ yield. ${ }^{1} \mathrm{H}$ NMR analysis revealed a coupling constant between $\mathrm{H}^{2}$ and $\mathrm{H}^{3}=8.0 \mathrm{~Hz}$, similar to that of previously reported, structurally related, cis derivatives. ${ }^{57-60}$ The stereochemical outcome of 
Chart 2. Chemical Structure of F-Hyps $12 a-d$ and the Corresponding Reference Compounds<smiles>CC(=O)[C@@H]1[C@@H](F)[C@@H](O)CN1C(C)=O</smiles>

$12 a$

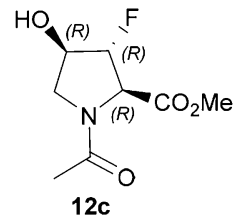

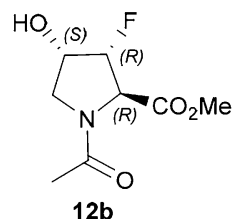

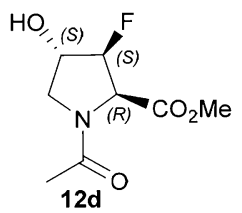

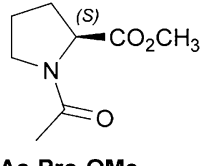

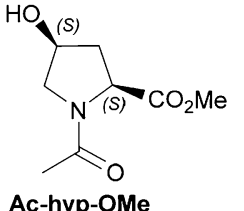

Ac-Pro-OMe
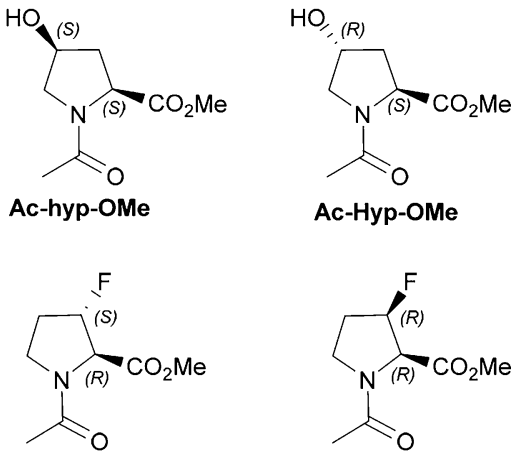

Ac-3-Fpro-OMe

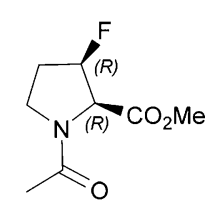

Ac-3-fpro-OMe

Table 1. Summary of Conformational Analysis, Second-Order Perturbation Energies, and H-Bond Donor Capacity of F-Hyps $12 \mathrm{a}-\mathrm{d}^{a}$

\begin{tabular}{|c|c|c|c|c|c|c|c|c|c|}
\hline compound & $\begin{array}{l}\text { ratio } \\
\text { trans:cis } b\end{array}$ & $\begin{array}{c}\mathrm{H}_{\mathrm{H} 2-\mathrm{H} 3} \\
(\mathrm{~Hz})\end{array}$ & $\bar{J}_{\mathrm{H} 2-\mathrm{H} 3}^{\text {calculated }}(\mathrm{Hz})$ & optimized ring pucker & $\begin{array}{l}\text { rel. } E \text { of conformer } \\
(\mathrm{kcal} / \mathrm{mol})\end{array}$ & $\begin{array}{c}\text { fraction of } \\
\text { conformer }(\%)^{c}\end{array}$ & $\begin{array}{l}\bar{E}_{\mathrm{n}_{\mathrm{O}} \rightarrow \pi_{\mathrm{C}=\mathrm{O}}^{*}}^{(2)} \\
(\mathrm{kcal} / \mathrm{mol})^{d}\end{array}$ & $\begin{array}{l}\bar{E}_{\mathrm{n}_{\mathrm{O} \rightarrow \pi_{\mathrm{C}}^{*}=\mathrm{O}}^{(2)}}^{*} \\
(\mathrm{kcal} / \mathrm{mol})^{e}\end{array}$ & $\begin{array}{l}\bar{V}_{\mathrm{a}}(r) \\
(\text { a.u. })^{f}\end{array}$ \\
\hline \multirow[t]{3}{*}{$12 a$} & \multirow[t]{3}{*}{$89: 11$} & \multirow[t]{3}{*}{4.6} & \multirow[t]{3}{*}{5.7} & twisted $C^{2}$-endo- $C^{3}$-exo & 0.8 & 12 & \multirow[t]{3}{*}{0.8} & \multirow[t]{3}{*}{1.1} & \multirow[t]{3}{*}{0.339} \\
\hline & & & & $\begin{array}{l}\mathrm{C}^{4} \text {-endo (with } \\
\text { transannular H-Bond) }\end{array}$ & 0.1 & 40 & & & \\
\hline & & & & $\mathrm{C}^{4}$-exo & 0.0 & 47 & & & \\
\hline \multirow[t]{2}{*}{$12 b$} & \multirow[t]{2}{*}{$85: 15$} & \multirow[t]{2}{*}{2.4} & \multirow[t]{2}{*}{1.2} & $\mathrm{C}^{4}$-endo & 0.0 & 92 & \multirow[t]{2}{*}{1.0} & \multirow[t]{2}{*}{-} & \multirow[t]{2}{*}{0.378} \\
\hline & & & & twisted $C^{3}$-endo- $-C^{4}$-exo & 1.4 & 8 & & & \\
\hline \multirow[t]{3}{*}{$12 \mathrm{c}$} & \multirow[t]{3}{*}{$71: 29$} & \multirow[t]{3}{*}{$<0.5$} & \multirow[t]{3}{*}{0.1} & $\mathrm{C}^{4}$-endo & 0.0 & 78 & \multirow[t]{3}{*}{0.9} & \multirow[t]{3}{*}{-} & \multirow[t]{3}{*}{0.357} \\
\hline & & & & $\begin{array}{l}\mathrm{C}^{4} \text {-endo (with } \\
\text { transannular H-Bond) }\end{array}$ & 0.8 & 21 & & & \\
\hline & & & & twisted $C^{3}$-endo- $C^{4}$-exo & 2.7 & 1 & & & \\
\hline \multirow[t]{2}{*}{$12 d$} & \multirow[t]{2}{*}{$87: 13$} & \multirow[t]{2}{*}{4.9} & \multirow[t]{2}{*}{7.0} & $\mathrm{C}^{3}$-exo & 0.0 & 60 & \multirow[t]{2}{*}{0.4} & \multirow[t]{2}{*}{1.7} & \multirow[t]{2}{*}{0.375} \\
\hline & & & & $\mathrm{C}^{5}$-endo & 0.2 & 40 & & & \\
\hline
\end{tabular}

${ }^{a}$ DFT calculations were carried out at the MN15-L/aug-cc-pVTZ(-F) level of theory in a water solvation continuum. See Supp. Table 3 for full results. ${ }^{b}$ Measured as the ratio of proton-decoupled ${ }^{19} \mathrm{~F}$ NMR signals in $\mathrm{D}_{2} \mathrm{O}$. ${ }^{c}$ Boltzmann population obtained from relative $E$. ${ }^{d}$ Charge transfer from acetyl $\mathrm{O}$ lone pair to $\pi^{*}$ orbital in the carbonyl in $\mathrm{C}^{2}$. ${ }^{e}$ Charge transfer from $\mathrm{F}$ lone pair to $\pi^{*}$ orbital in the carbonyl in $\mathrm{C}^{2} .{ }^{f}$ The Kenny electrostatic potential correlates with $\mathrm{H}$-bond donor capacity. ${ }^{30,61}$

the fluorination was in contrast with the observations made on the alkylation of the same ketone by Zanato et al., ${ }^{57}$ which mainly occurred from the less hindered face of the enolate 8 . Subsequent reduction with sodium borohydride in ethanol/ THF exclusively afforded the all-cis F-Hyp 10. The stereochemistry of compound $\mathbf{1 0}$ was confidently assigned by means of NMR experiments. The relative intensity of NOESY peaks for $\mathrm{H}^{2}-\mathrm{H}^{3}$ and $\mathrm{H}^{3}-\mathrm{H}^{4}$ were compatible with a cis arrangement of $\mathrm{H}^{2}-\mathrm{H}^{3}-\mathrm{H}^{4}$, and the relative intensity of the ${ }^{19} \mathrm{~F}-{ }^{1} \mathrm{H}$ HOESY peaks for $\mathrm{H}^{2}-\mathrm{F}$ and $\mathrm{H}^{4}-\mathrm{F}$ (equally low) were compatible with a trans arrangement of the $\mathrm{F}$ atom with $\mathrm{H}^{2}$ and $\mathrm{H}^{4}$. Moreover, a coupling constant of $\mathrm{J}_{\mathrm{H} 2-\mathrm{H} 3}=8.7 \mathrm{~Hz}$ in 10 was found, in accordance with the cis derivatives previously prepared. ${ }^{57-60}$ This assignment was subsequently confirmed by X-ray diffraction of 10, which crystallized with a transannular hydrogen bond between the carboxylate and the hydroxyl groups (Figure 2B). Mitsunobu esterification of 10 with 4nitrobenzoic acid followed by treatment with lithium hydroxide led to the inverted alcohol, and no methyl ester hydrolysis was observed. Accordingly, the relative intensity of the ${ }^{19} \mathrm{~F}-{ }^{1} \mathrm{H}$ HOESY peak for $\mathrm{H}^{2}-\mathrm{F}$ was compatible with a trans arrangement, whereas the intensity for $\mathrm{H}^{4}-\mathrm{F}$ was only compatible with a cis arrangement, being $150 \%$ higher than that of $\mathrm{H}^{2}-\mathrm{F}$. Deprotection of the carboxylate could be achieved only after removal of the Pf group. To this end, 11 was first treated with 5\% trifluoroacetic acid (TFA) in DCM in the presence of triisopropylsilane as carbocation scavenger, then with $\mathrm{LiOH}$ at $0{ }^{\circ} \mathrm{C}$ in water. To obtain F-Hyps building blocks, useful for further manipulations, the free F-Hyps were transformed into the Boc- or Fmoc-protected amino acids by reaction with Boc- or Fmoc- $N$-succinimidyl carbonate and sodium bicarbonate in aqueous dioxane, respectively.

2.2. Conformational Analysis and H-Bond Donor Capacity of F-Hyps. Recognition of Hyp by VHL is highly stereoselective and conformation-dependent: the $\mathrm{C}^{4}$-exo ring pucker of Hyp is essential to locate the hydroxyl group within a well-defined hydrogen-bond network in the Hyp-binding pocket. Additionally, binding of HIF- $1 \alpha$ peptides and VHL ligands requires adoption of a trans conformation of the prolyl tertiary amide (Figure 1B). We therefore became interested in determining to what extent addition of the highly electronegative $\mathrm{F}$ atom adjacent to the hydroxyl group in Hyp would impact the $\mathrm{C}^{4}$-exo ring pucker of the pyrrolidine, affect the donor capacity of the adjacent hydroxyl group, and modulate the abundance of trans prolyl amide. We hypothesized that modulation of these conformational and molecular properties could significantly fine-tune the binding affinity to VHL and consequently be exploited for a novel class of VHL ligands.

We first studied both experimentally and computationally the conformational preferences of $\mathrm{N}$-acetylproline methylesters 12a-d (Chart 2), extending the analysis to the $(3 R, 4 R)$ - and $(3 S, 4 R)$-3-fluoro-4-hydroxyproline derivatives. Analogous 
A)

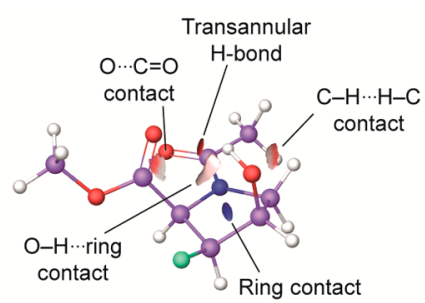

C)
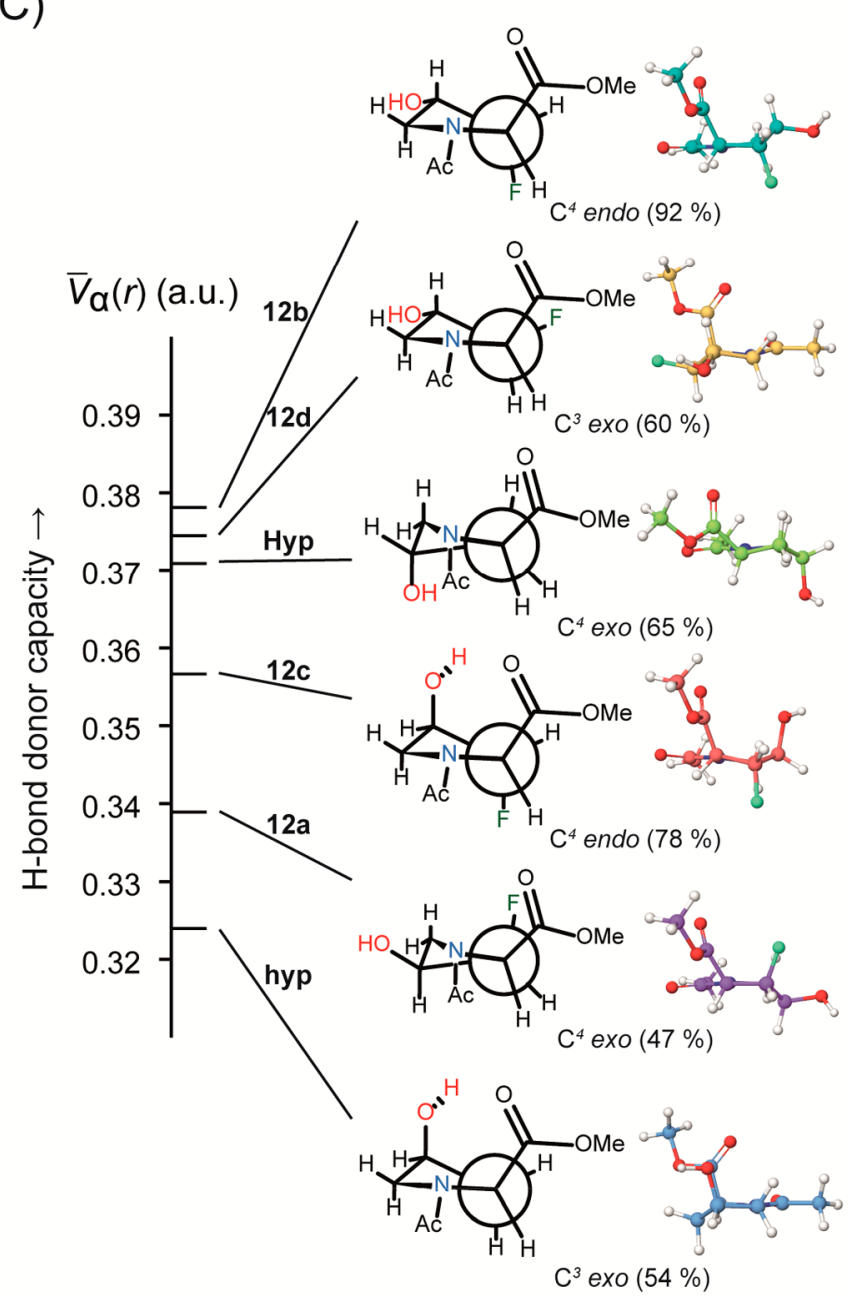
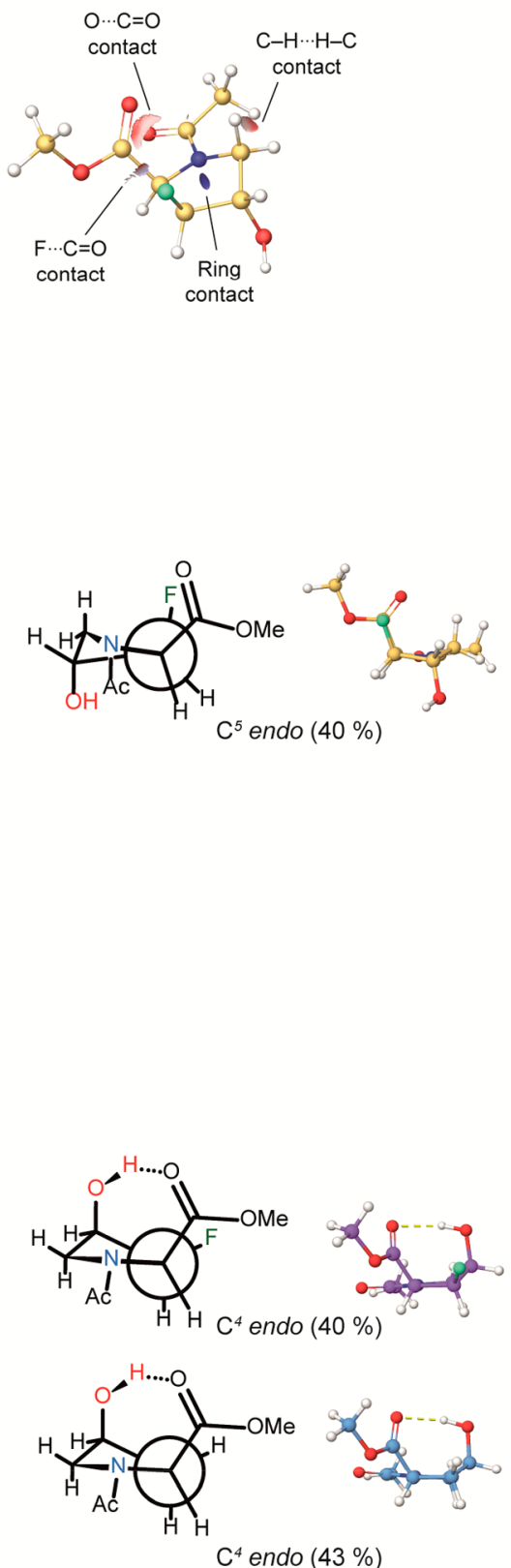

Figure 3. Topological and conformational analysis and H-bond donating capacity of F-Hyps. NCI isosurface plots for 12a (A) and 12d (B). ${ }^{62}$ Reduced density gradient shown at an isovalue of 0.3 , with interaction strength colored red (attractive), white (van der Waals contact), and blue (repulsive), ranging from -0.02 to 0.05 a.u. (C) Visualization of the H-bond donor capacity and major conformers of 12a-d, Ac-Hyp-OMe, and Ac-hyp-OMe. The Kenny electrostatic potential $\left(V_{\alpha}(r)\right)$ correlates with the H-bond donor capacity of the $\mathrm{OH}^{30}$

methylesters have been previously used in the literature as reliable model compounds to study the conformational preferences of the (4R)-hydroxyproline (Hyp), (4S)-hydroxyproline (hyp), (3S)-fluoroproline (3-Fpro), and (3R)fluoroproline (3-fpro) moieties. ${ }^{5,13}$ The compounds $12 \mathbf{a}-\mathbf{d}$ were synthesized from $\mathbf{6 a}-\mathbf{d}$ by (trimethylsilyl)diazomethane esterification, followed by Boc deprotection and $\mathrm{N}$-acetylation. To predict molecular properties of compounds in solution, we performed density functional theory (DFT) calculations of trans $C^{4}$-endo and exo puckers of $12 a-d$ and the reference compounds Ac-Hyp-OMe, Ac-hyp-OMe, Ac-3-Fpro-OMe, Ac-3-fpro-OMe, and Ac-Pro-OMe (Chart 2). All calculations were carried out at the MN-15L/aug-cc-pVTZ(-F) level of theory in a water solvation continuum (see Computational
Methods and Supp. Table 1 for details on the choice of density functional). The protocol correctly anticipates the ring pucker preferences of model compounds Ac-Pro-OMe, Ac-3-Fpro$\mathrm{OMe}$, and Ac-Hyp-OMe and predicts $J_{\mathrm{H} 2-\mathrm{H} 3}$ couplings for AcHyp-OMe, Ac-hyp-OMe, and F-Hyps 12a-d in excellent agreement with the corresponding NMR-observed shifts (Table 1 and Supp. Table 3).

Analysis of the abundance of $\mathrm{C}^{4}$-endo and exo ring puckers in F-Hyps 12a-d revealed that conformational preferences upon 2,3-trans fluorination are driven by the stabilizing gauche conformation between the $\mathrm{N}$ and the $\mathrm{F}$ atoms. Indeed, 2,3trans fluorination of Ac-hyp-OMe to yield 12c further stabilizes the $\mathrm{C}^{4}$-endo pucker of hyp (99\% abundance), whereas 2,3-trans fluorination of Ac-Hyp-OMe to yield 12b 
shifts the natural preference of hyp from $\mathrm{C}^{4}$-exo to $\mathrm{C}^{4}$-endo (92\% abundance). The case of 2,3-cis fluorination of hydroxyproline was found to be more complex. The steric congestion surrounding $\mathrm{C}^{3}$ in 3 -fpro has been invoked to justify the reduced conformational preference of the ring for either pucker. $^{13}$ Consistently, F-Hyps 12a and 12d showed very modest preference to adopt a $\mathrm{C}^{4}$-endo or -exo ring pucker, with $\sim 50 \%$ abundance of each $\left(\Delta E_{\text {endo/exo }}<0.25 \mathrm{kcal} / \mathrm{mol}\right)$. Noncovalent contacts in the molecules were studied by topological noncovalent interactions (NCI) analysis ${ }^{62}$ of the electron density distribution. In 12a, the NCI study showed a transannular $\mathrm{H}$-bond between the hydroxyl group and the carbonyl $\mathrm{O}$ in $\mathrm{C}^{2}$, along with a consistent van der Waals contact between the hydroxyl proton and the ring in 12a. In contrast, in 12d, NCI analysis detected attractive $\mathrm{F} \cdots \mathrm{C}=\mathrm{O}$ contacts (Figure $3 \mathrm{~A}$ and $\mathrm{B}$ ). The ring pucker of the predicted major components of F-Hyps $12 a-c$ was captured in the related crystallized compounds $4 \mathrm{a}-\mathrm{c}$ using small-molecule $\mathrm{X}$ ray crystallography (Figure 2 and Supp. Figure 1), providing further support for the theoretical calculations. Taken together, the conformational analysis revealed that fluorination of AcHyp-OMe to yield $(3 R, 4 S)$ - and (3S,4S)-3-fluoro-4-hydroxyprolines $\mathbf{1 2 b}$ and $12 \mathrm{~d}$ stabilizes a $\mathrm{C}^{4}$-endo pucker and consequently would be expected to lower the population of the desired $\mathrm{C}^{4}$-exo ring pucker required for binding to VHL.

To quantify the energetic extent of the potential $n_{\mathrm{O}} \rightarrow \pi_{\mathrm{C}=\mathrm{O}}^{*}$ charge transfer in F-Hyps 12a-d, we next performed natural bond order (NBO) analyses. ${ }^{63}$ This $\mathrm{n}_{\mathrm{O}} \rightarrow \pi_{\mathrm{C}=\mathrm{O}}^{*}$ interaction is known to stabilize the trans conformer of the amide, ${ }^{64}$ which is critical for binding of Hyp to VHL. ${ }^{65}$ We compared the $\mathrm{n}_{\mathrm{O}} \rightarrow$ $\pi_{\mathrm{C}=\mathrm{O}}^{*}$ charge transfer energies with the trans:cis ratio of F-Hyp derivatives $12 a-d$ (observed by ${ }^{19} \mathrm{~F} \quad \mathrm{NMR}$ ) and of 4hydroxyprolines and 3-fluoroprolines reported in the literature $^{13}$ (Table 1 and Supp. Table 3). The computational and experimental values for Ac-Hyp-OMe and Ac-hyp-OMe were in good agreement (higher charge transfers are indicative of higher abundance of the trans conformer). Instead, the trans:cis ratio for F-Hyps $12 a-d$ did not correlate with $n_{O}$ $\rightarrow \pi_{\mathrm{C}=\mathrm{O}}^{*}$ energies. This has been also reported in 3fluoroproline, ${ }^{9}$ suggesting that a combination of other factors, including inductive and steric effects, might be involved. A higher amount of cis amide was observed by NMR for $\mathbf{1 2 b}, \mathbf{c}$, featuring the fluorine atom in the 3- $(R)$ position, compared to $12 a, d$, bearing the fluorine atom in the $3-(S)$ position. This correlates well with the trans:cis ratio experimentally measured for 3-fluoroprolines. ${ }^{13}$ Based on the observed trans:cis ratio in $\mathbf{1 2 b}$,d by NMR, we conclude that fluorination of Hyp does not stabilize the trans amide conformer, which would otherwise be expected to enhance the affinity of VHL ligands.

We then became interested in assessing whether fluorination could lead to a strengthening of the H-bond network of Hyp in the recognition site of VHL through inductive effects. To address this question, we calculated the weighted electrostatic potential $\bar{V}_{\alpha}(r)$ of F-Hyps 12a-d, evaluated at a distance of $0.55 \AA$ from the hydroxyl hydrogen atom along the $\mathrm{O}-\mathrm{H}$ bond (Table 1 and Figure 3C). ${ }^{57}$ This descriptor correlates linearly with relative $\mathrm{H}$-bond acidity $\left(\mathrm{p} K_{\mathrm{AHY}}\right)$, which is a measure of the H-bond donor capacity of the hydroxyl group. ${ }^{30,66}$ An increase in H-bond donor capacity in Hyp could be potentially exploited to strengthen its H-bond with His115 (Figure 1B). However, fluorination of Ac-Hyp-OMe to yield $\mathbf{1 2 b}$ and $\mathbf{1 2 d}$ induced only a modest increase in the H-bond acidity of the hydroxyl $\mathrm{H}$ atom, regardless of the stereochemistry in $\mathrm{C}^{3}$. This suggests that the inductive effect of the fluorine may compete with a transannular $\mathrm{H}$-bond to the $\mathrm{F}$ atom in the compounds. $^{30,67}$ Nonetheless, we observed relatively long F... $\mathrm{H}-\mathrm{O}$ distances $\left(2.5-3.3 \AA\right.$ ) along with undetectable $\mathrm{n} \rightarrow \sigma^{*}$ charge transfer between the lone pairs in the $\mathrm{F}$ and the acceptor $\sigma_{\mathrm{O}-\mathrm{H}}^{*}$ orbital, as by $\mathrm{NBO}$ analysis. Topological analysis of electron densities using NCI did not reveal any F... $\mathrm{H}-\mathrm{C}$ contact, either. Thus, capture of the proton in $\mathbf{1 2 b}$ and 12d may arise from a weak electrostatic stabilization rather than a typical H-bond. ${ }^{30}$ Together, these analyses indicate that $\mathrm{C}^{3}$ fluorination of Hyp may only modestly improve the $\mathrm{H}$ bond donor capacity of the hydroxyl group, regardless of the stereochemistry in $\mathrm{C}^{3}$. For completeness, we also studied the proton acidity of Ac-hyp-OMe and its fluoro derivatives 12a and 12c. A substantial decrease in $\mathrm{H}$-bond donor capacity of the hydroxyl group in Ac-hyp-OMe compared to Ac-HypOMe was anticipated, since in Ac-hyp-OMe the hydroxyl group engages in a transannular $\mathrm{H}$-bond with the carbonyl $\mathrm{O}$ in $\mathrm{C}^{2}$. Fluorination of Ac-hyp-OMe to form 12a and 12c induces a higher increase in $\mathrm{H}$-bond donor capacity compared to fluorination of Ac-Hyp-OMe, suggesting that in those compounds the inductive effect of fluorine is not competing with an $\mathrm{F} \cdots \mathrm{H}-\mathrm{O}$ contact. The increase in acidity is utmost notorious in $12 \mathrm{c}$, in which the fluorine atom is antiperiplanar to the $\mathrm{O}$. Indeed, it has been proposed that this arrangement increases the electronegativity of the fluorine. ${ }^{30}$ The increasing acidity of the protons (Ac-hyp-OMe $<12 \mathrm{a}<12 \mathrm{c}$ ) can be further rationalized by the decreasing fraction of transannular $\mathrm{H}$-bond (Ac-hyp-OMe > 12a > 12c, Figure 3C), which at the same time is consistent with an increase in the H-bond distance. Additional topological analyses of electron densities and second-order perturbation energies were also consistent with a weakening of the transannular $\mathrm{H}$-bond upon fluorination of Ac-hyp-OMe, particularly in 12c (Supp. Table 4). Thus, $\mathrm{C}^{3}$ fluorination of Hyp and hyp has a distinct impact on proton acidity. In Hyp the inductive effect of $\mathrm{F}$ is compensated by a weak electrostatic stabilization of the $\mathrm{H}$ atom. In contrast, in hyp the acidity increases in a stereoselective fashion assisted by a weakening of the transannular H-bond.

Taken together, the conformational analysis of F-Hyps $\mathbf{1 2 b}, \mathbf{d}$ indicates that $\mathrm{C}^{3}$-fluorination of Ac-Hyp-OMe, irrespective of the relative stereochemistry, does not modulate conformational preferences and hydrogen-bonding potential of the Hyp core fragment in the directions that would be expected to strengthen the binding affinity of VHL ligands. First, we do not observe stabilization of the $\mathrm{C}^{4}$-exo ring pucker, which is critical for recognition (Figure 1B). Rather, we observe a preference for the $\mathrm{C}^{4}$-endo pucker in both $\mathbf{1 2 b}$ and 12d, albeit to varying extent. Second, we do not detect an increase in the abundance of the trans amide conformer by NMR, which is required for binding to VHL. And third, fluorination induces only a very minor increase in the H-bond donor capacity of the hydroxyl group, regardless of the stereochemistry in $\mathrm{C}^{3}$. Nevertheless, fluorine often participates in noncanonical ligand-protein interactions that cannot be inferred from studying the isolated ligand and that generally behave in a highly nonadditive fashion, making it difficult to predict them computationally. We therefore decided to proceed to interrogate the molecular recognition of F-Hypcontaining peptides and peptidomimetics by VHL experimentally. 


\subsection{Synthesis and Biophysical and Structural Binding} Studies of F-Hyp-Containing Peptides of HIF-1 $\alpha$. Hypcontaining HIF- $1 \alpha$ epitope peptides are excellent model substrates for studying the binding to VHL, as their binding mode and affinities have been extensively characterized. ${ }^{32,33,37}$ To assess to what extent VHL recognizes F-Hyps as an artificial post-translational modification of proline, modified peptides from the $\mathrm{C}$-terminal oxygen-dependent degradation domain of HIF-1 $\alpha$ (of sequence DEALA(Hyp)YIPMDDDFQLRSF) that contained $(3 S, 4 S)$ - or $(3 R, 4 S)$-FHyps in place of Hyp were synthesized (Chart 3).

Chart 3. Structures of Model HIF-1 $\alpha$ Peptides Biophysically Evaluated in This Work

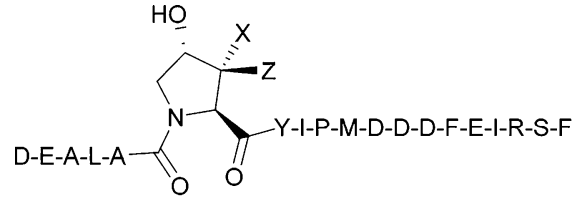

13a: $X=F, Z=H$

13b: $X=H, Z=F$

13c: $X=Z=H$

To this end, Fmoc-protected (3S,4S)- and (3R,4S)-F-Hyps were prepared from the corresponding Boc-protected amino acids $\mathbf{6 b}$ and $\mathbf{6 d}$ via acidic deprotection of the Boc group followed by Fmoc installation by reaction with Fmoc-OSu. The first 13 C-terminal amino acids (YIPMDDDFQLRSF) of the 19-mer peptides were coupled via conventional automated solid-phase peptide synthesis on a Rink amide resin before the $N$-Fmoc-protected F-Hyps were manually coupled to resinbound peptide via HATU/HOAT coupling. After Fmoc deprotection of F-Hyps, peptide elongation was performed manually, the N-terminal Fmoc group was removed, and the peptides were cleaved from the resin using a TFA/ triisopropylsilane $/ \mathrm{H}_{2} \mathrm{O} \quad(95: 2.5: 2.5)$ mixture. The crude peptides were purified by preparative HPLC to obtain the epimeric peptides 13a,b. The corresponding peptides containing the $(3 S, 4 R)$ - and $(3 R, 4 R)$-F-hyp were not prepared because it is well-known that such stereochemical arrangement of the hydroxyl group is not tolerated in the VHL binding site. ${ }^{8}$ Binding of the modified F-Hyp-containing peptides $13 \mathbf{a}, \mathbf{b}$ to $\mathrm{VBC}$ was assessed using isothermal titration calorimetry (ITC, Figure 4A). Both peptides 13a,b presented nanomolar binding affinity to VBC $\left(K_{\mathrm{d}}=12 \pm 2 \mathrm{nM}\right.$ and $52 \pm 3 \mathrm{nM}$, respectively, Table 2). Remarkably, 13a showed comparable binding affinity to the native peptide $13 \mathrm{c}$ (prepared as previously reported), ${ }^{37}$ for which a $K_{\mathrm{d}}=11 \pm 1 \mathrm{nM}$ was measured (Table 2). Among the fluorinated peptides, 13a, containing the $(3 R, 4 S)$-F-Hyp isomer, showed a 4-fold higher affinity for VBC than $\mathbf{1 3 b}$, suggesting that VHL can recognize F-Hyps in a diastereoselective fashion.

To elucidate the binding mode of F-Hyp-containing HIF peptides, we solved the cocrystal structure of the ternary complex VBC with peptide $13 a$ (to a resolution of $1.8 \AA$ ) and compared it to the cocrystal structure of the native peptide 13c. ${ }^{37}$ The VBC:13a complex crystallized in the same space group as VBC:13c $\left(P_{3} 2_{1} 2\right)$, and the overall unit cell parameters and crystal packing were conserved. The F-Hypcontaining peptide 13a was found to adopt an identical binding mode when compared to the native peptide $13 \mathrm{c}$
A

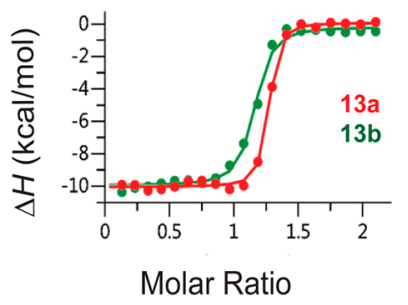

B
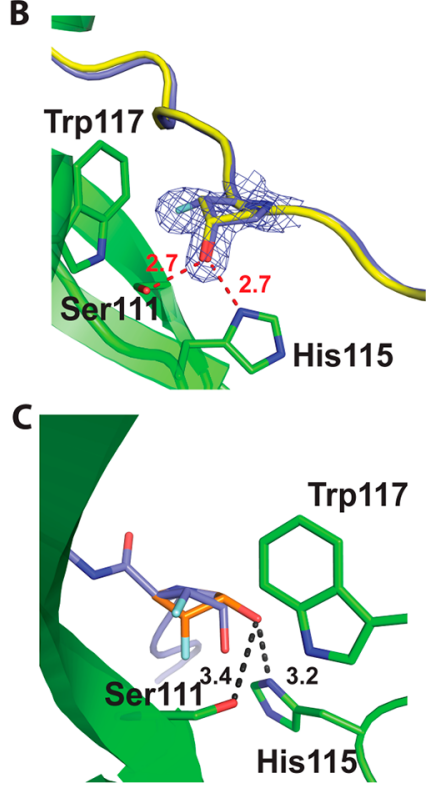

Figure 4. Binding affinity and binding mode of F-Hyp-containing HIF- $1 \alpha$ peptides. (A) Overlay of ITC titration curves obtained for FHyps-containing peptides 13a,b against VBC. (B) Crystal structure of peptide 13a (blue) in complex with VBC (green) overlaid with the structure of VBC in complex with the Hyp-containing peptide 13c (yellow). Key hydrogen bond interactions and distances in Å between F-Hyp and Ser111 and His115 of VHL are shown in red; the $F_{0}-F_{c}$ omit map contoured at $3.5 \sigma$ around the F-Hyp residue is shown in blue. (C) Overlay of the crystal structure of peptide 13a (blue) in complex with VBC (green) with the structure of F-Hyp in the $\mathrm{C}^{4}$ endo conformation (orange, from small-molecule X-ray crystallography of $\mathbf{4 b}$ ). In black: distances in $\AA$ between the hydroxyl group of F-Hyp in the $\mathrm{C}^{4}$-endo conformation (in orange) and the residues Ser111 and His115 of VHL.

(Figure 4B) and other HIF peptides, ${ }^{32,33}$ with all hydrogen bonds being conserved. After structural refinement, the pyrrolidine ring of the $(3 R, 4 S)$-F-Hyp residue was modeled in a $\mathrm{C}^{3}$-endo conformation, as this satisfied better the extra electron density. However, the resolution was not sufficiently high to exclude the possibility of a $\mathrm{C}^{4}$-exo pucker, which was observed in the case of the cocrystal of $\mathrm{VBC}: 13 \mathrm{c}$, as the conformational difference between the two states $\left(\mathrm{C}^{3}\right.$-endo and $\mathrm{C}^{4}$-exo) is very subtle. In the bound state, the hydroxyl group of the 13a F-Hyp forms two key hydrogen bonds to the side chains of His115 and Ser111, exactly as observed for Hyp in the native peptide $13 \mathrm{c}$ (Figure $4 \mathrm{~B}$ ). The newly introduced fluorine atom forms close contacts with an aromatic $\mathrm{C}-\mathrm{H}$ of the indole ring of Trp117 ( $3.3 \AA$ ), the hydroxy group of Ser111 $(3.2 \AA)$, and the carbonyl of His110 (3.2 $\AA)$. An overlay of the VHL-cocrystallized peptide 13a with the small-molecule crystal structure of F-Hyp $\mathbf{4 b}$ (Figure 4C) reveals that, in order to preserve the key H-bond network of the Hyp core, the F-Hyp 
Table 2. Thermodynamic Binding Parameters of Peptides 13a-c and Ligands 14a,b to VBC

\begin{tabular}{|c|c|c|c|c|c|}
\hline & $K_{\mathrm{d}}(\mathrm{nM})$ & $\Delta H(\mathrm{kcal} / \mathrm{mol})$ & $-T \Delta S(\mathrm{kcal} / \mathrm{mol})$ & $\Delta G(\mathrm{kcal} / \mathrm{mol})$ & N.R. ${ }^{a}$ \\
\hline $13 a$ & $12 \pm 2$ & $-10.1 \pm 0.1$ & $-0.75 \pm 0.05$ & $-10.8 \pm 0.1$ & 2 \\
\hline $13 b$ & $52 \pm 3$ & $-9.7 \pm 0.3$ & $0.0 \pm 0.2$ & $-9.94 \pm 0.04$ & 2 \\
\hline $13 c$ & $11 \pm 1$ & $-12.8 \pm 0.1$ & $2.0 \pm 0.2$ & $-10.9 \pm 0.1$ & 2 \\
\hline $14 a$ & $244 \pm 6$ & $-7.2 \pm 0.5$ & $-1.8 \pm 0.5$ & $-9.02 \pm 0.01$ & 3 \\
\hline $14 b$ & $3,080 \pm 10$ & $-3.9 \pm 0.5$ & $-3.8 \pm 0.4$ & $-7.55 \pm 0.03$ & 2 \\
\hline
\end{tabular}

pyrrolidine needs to rearrange from its predominant $\mathrm{C}^{4}$-endo conformation to a $\mathrm{C}^{3}$-endo/ $\mathrm{C}^{4}$-exo pucker that is only modestly populated in solution, according to DFT calculations (Table 1). This suggests that the pyrrolidine ring of the F-Hyp in 13a must undergo a significant change in the conformational equilibrium to bind to the protein, possibly at the expense of the $\Delta G$ of binding. Because only a very subtle difference in the $\Delta G$ of binding was found between the native peptide $13 \mathrm{c}$ and 13a (Table 2), presumably the energetic penalty required for the pucker rearrangement from free to bound state must be compensated for by significantly favorable contacts between the protein and the ligand environment around the newly introduced $\mathrm{F}$ atom.

2.4. Synthesis, Binding Affinity, and X-ray Crystal Structure of F-Hyp-Containing VHL Ligands. Encouraged by the positive results on the binding of F-Hyp-containing peptides to VHL, we proceeded replacing the Hyp core of the prototypical ligand VH032 (Figure 1C, ref 39) with $(3 S, 4 S)$ and $(3 R, 4 S)$-F-Hyp to study the molecular recognition within the context of VHL ligands. Ligands 14a,b (Figure 5A) were

A

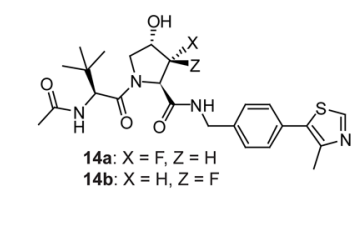

C

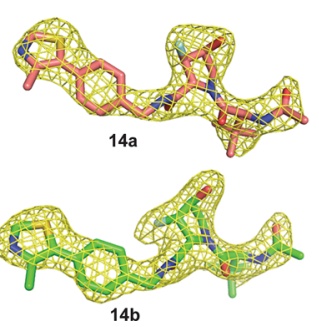

B

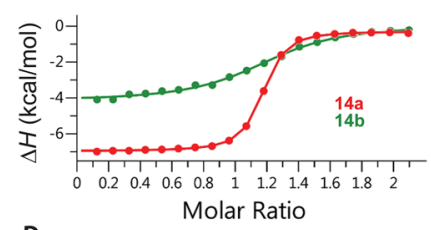

D

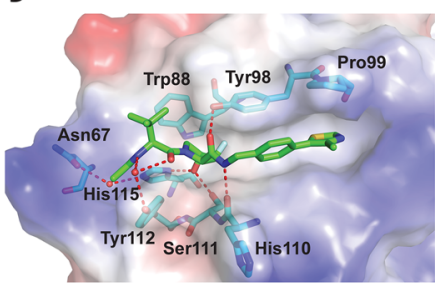

Figure 5. Binding affinity and binding mode of F-Hyp-containing VHL ligands. (A) Chemical structure of ligands 14a,b. (B) Overlay of ITC titration curves obtained for the F-Hyps-containing ligands 14a,b against VBC. (C) The $F_{0}-F_{\mathrm{c}}$ omit map contoured at $4 \sigma$ (shown in yellow) for ligands $\mathbf{1 4 a}, \mathbf{b}$ in complex with VBC. (D) Crystal structure of ligand $\mathbf{1 4 b}$ in complex with VBC. Key $\mathrm{H}$-bond interactions are shown in red.

prepared according to previously reported procedures, ${ }^{38-40}$ and no particular optimization of reaction conditions was required. Binding of the modified F-Hyp-containing VHL ligands 14a,b to VBC was assessed by ITC (Table 2, Figure 5B). Ligand 14a retained nanomolar binding affinity to VBC (Table 2), which is within 2-fold of the parent Hyp-containing ligand VH032 $\left(K_{\mathrm{d}}=185 \pm 7 \mathrm{nM}\right) .{ }^{39}$ In contrast, ligand $\mathbf{1 4 b}$ showed a much lower affinity (Table 2), corresponding to a reduction in binding affinity of almost 20 -fold compared to

VH032. The $\Delta H$ of binding measured for the VHL ligands correlated well with the binding affinities.

These results confirmed the trend observed for the F-Hypcontaining peptides: the $(3 R, 4 S)$ isomer of F-Hyp binds to VBC with higher affinity than the $(3 S, 4 S)$ isomer, as a result of diastereoselective recognition of F-Hyps. As expected, in the case of small molecules, the difference in binding affinity between the two diastereoisomers is greater than in the case of peptides, as the binding of such ligands relies on fewer contacts and interactions beyond the most energetically favorable ones involving the core hydroxyproline moiety. To elucidate the binding mode of the two epimers of F-Hyp-containing ligands to VHL and to rationalize the difference in binding affinity, we soaked crystals of VBC into solutions of $\mathbf{1 4 a}, \mathbf{b}$ and solved the crystal structures of the binary complexes. No difference in the binding mode between the two diastereoisomers was found (Figure 5C,D and Supp. Figure 2), and moreover the binding mode of the nonfluorinated analogue (VH032) was recapitulated by the fluorinated analogues 14a,b. Similarly to what was observed in the case of peptide 13a, the fluorine atom in 14a forms close contacts with an aromatic $\mathrm{C}-\mathrm{H}$ of the indole ring of Trp117 (3.2 $\AA$ ), the hydroxyl group of Ser111 (3.2 $\AA$ ), and the carbonyl of His110 (3.1 $\AA$ ). For $14 \mathrm{~b}$, close contacts between the fluorine atom and $\operatorname{Trp} 117(3.3 \AA)$ and the phenolic group of Tyr98 (3.0 $)$ were found. The resolution of the structures $(2.7 \AA \AA$ for $14 \mathrm{a}$ and $2.3 \AA$ for $14 \mathrm{~b}$ ) did not allow us to unambiguously determine the ring puckering of the $\mathrm{F}$ Hyps of $\mathbf{1 4 a} \mathbf{a}, \mathbf{b}$, which was modeled as $\mathrm{C}^{4}$-exo, as for the nonfluorinated ligand VH032 (Figure 5C,D and Supp. Figure 2 ). We therefore conclude that, as in the case of F-Hypcontaining peptides, a comparably large energetic penalty must be overcome for the ligands to bind to VHL in a $\mathrm{C}^{4}$-exo conformation.

To provide insights into the preferential recognition of 14a by VHL, we carried out quantum mechanics/molecular mechanics ( $Q M / M M)$ single-point energy (SPE) calculations in a water solvation continuum, using the ligand-bound crystal structures of VHL in complex with VH032, ${ }^{39} \mathbf{1 4 a}$ and 14b. The obtained molecular electrostatic potential surfaces reveal a markedly distinct effect of fluorination in the charge density around the hydroxyproline core (Figure 6) and allow for the rationalization of the observed preferential binding. In 14a, the fluorine induces a substantial increase in the electrostatic potential surrounding the hydroxyl O compared to VH032 and 14b (note the yellow to red shift in Figure 6, bottom view). In contrast, in $\mathbf{1 4 b}$ the fluorine creates an electron-rich bump that contrasts with the smaller, electron-poor surface of the $\mathrm{H}$ in VH032 (note the blue to green shift in Figure 6, top view). These alterations are anticipated to affect the molecular recognition. An increase in the electron density of the hydroxyl group, as in 14a, would strengthen its H-bond acceptor interaction with the side chain of Ser111. Conversely, the bump and the inversion of the electrostatic potential induced 

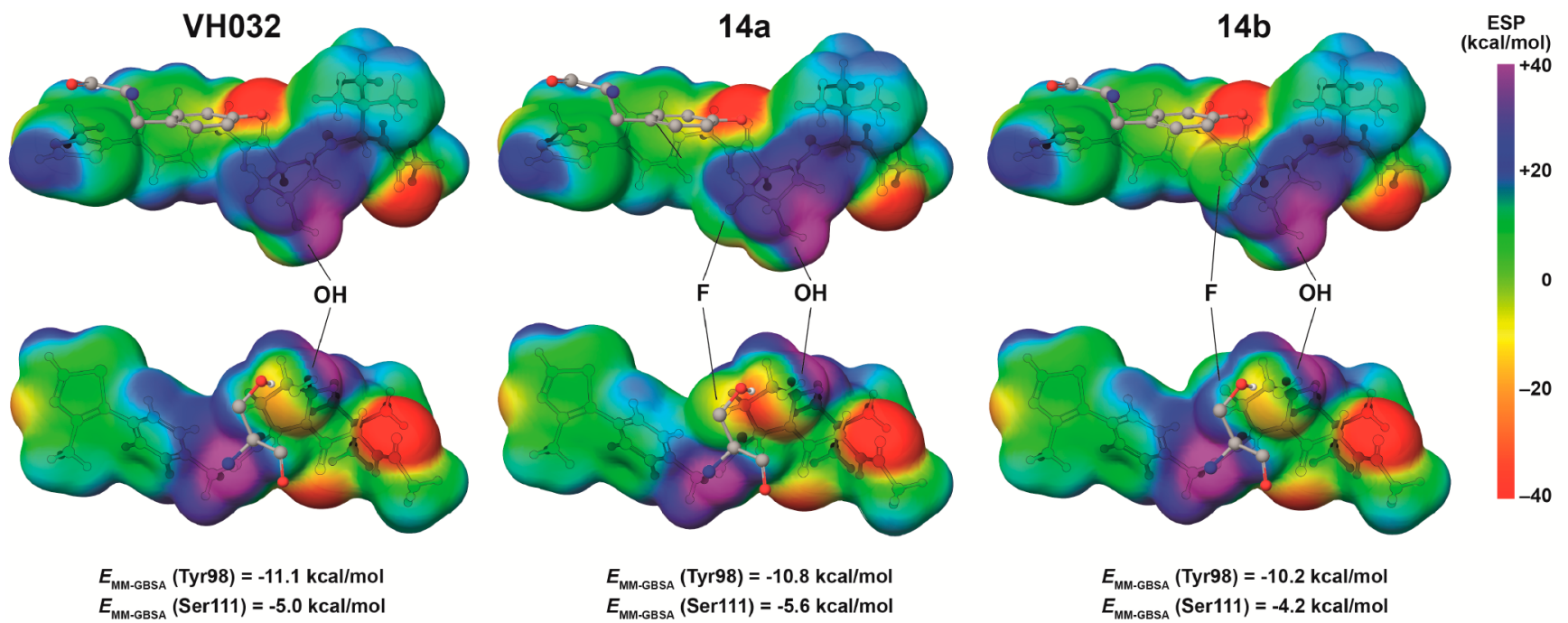

Figure 6. Structural basis of diasteroselective recognition of F-Hyps by VHL. Molecular electrostatic potential surface of VH032, 14a, and 14b in complex with VHL, obtained using QM/MM SPE calculations in a water solvation continuum at the MN15-L/aug-cc-pTVZ(-F) level of theory. Tyr98 and Ser111 from VHL are shown in gray, and their interaction energy as per MM-GBSA calculations is shown below.

by fluorine in $\mathbf{1 4 b}$ are potentially disruptive for binding because they face the electron-rich aromatic system of Tyr98, which is at a short distance of $3.0 \AA$ (Figures 5D and 6) and known to be very sensitive toward binding of small molecules. ${ }^{65}$ These observations were consistent with MM/ generalized-Born surface area (MM-GBSA) calculations performed using the same crystal structures (Figure 6). The MM-GBSA interaction energy $\left(E_{\mathrm{MM}-\mathrm{GBSA}}\right)$ of Ser111 was higher for VHL in complex with 14a than with VH032 and 14b $\left(\Delta E_{\mathrm{MM}-\mathrm{GBSA}}=-0.6\right.$ and $-1.4 \mathrm{kcal} / \mathrm{mol}$, respectively $)$, whereas the interaction of Tyr98 was weakened when $14 \mathrm{~b}$ was bound, compared to VH032 and 14a $\left(\Delta E_{\mathrm{MM}-\mathrm{GBSA}}=+0.9\right.$ and $+0.6 \mathrm{kcal} / \mathrm{mol}$, respectively).

We next investigated the impact of fluorination on the pharmacokinetic properties of hydroxyproline-containing compounds in the context of VHL ligands 14a,b (Table 3). Despite

Table 3. Cellular Pharmacokinetics Parameters of VHL Ligands 14a,b

$\begin{array}{lcccc} & \begin{array}{c}\text { mouse microsomal } \\ \text { stability }(\mathrm{mL} / \mathrm{min} / \mathrm{g} \\ \text { liver })\end{array} & \begin{array}{c}\text { plasma } \\ \text { stability } T_{1 / 2} \\ (\mathrm{~min})\end{array} & \begin{array}{c}\text { permeability } \\ (\mathrm{PAMPA}) \\ \left(\mathrm{nm} \mathrm{s}^{-1}\right)\end{array} & \begin{array}{c}\mathrm{CHI} \\ \log D_{7.4}\end{array} \\ \text { VH032 } & 0.70^{a} & >180^{a} & 1.2^{a} & 0.90^{a} \\ \text { 14a } & <0.50 & >180 & 2.3 & 1.30 \\ \text { 14b } & 0.68 & >180 & 0.81 & 1.30\end{array}$

${ }^{a}$ Values from Frost et al. ${ }^{40}$

a small increase in $\log D_{7.4}$ upon fluorination, microsomal stability of compound $\mathbf{1 4 b}$ was similar to that of the reference compound VH032, while ligand 14a proved to be even more metabolically stable. F-Hyp containing VHL ligands also retained high plasma stability. We also performed a parallel artificial membrane permeability assay (PAMPA) to measure the passive permeability of $\mathbf{1 4 a} \mathbf{b}$. The compounds exhibit stereodependent permeability in spite of the same $\log D_{7.4}$ value (Table 3 ), with 14a exhibiting higher permeability than the parent nonfluorinated ligand VH032.

Taken together, the crystal structures of VHL in complex with $\mathbf{1 4 a} \mathbf{a} \mathbf{b}$ reveal that diastereoselective recognition of $14 \mathbf{a}$ is mediated by strengthening of the $\mathrm{H}$-bond acceptor interaction with Ser111, which stabilizes the less abundant $C^{4}$-exo ring pucker of the compound (Table 1). This induced fit of the ligand is reflected in a slight loss in binding affinity of 14a compared to the Hyp-containing ligand VH032. Instead, steric and electronic repulsions of the fluorine with Tyr98 explain the significant loss of binding affinity in 14b. Additionally, we found that F-Hyps-containing compounds are metabolically stable and that fluorination of Hyp increases its lipophilicity. These positive data qualify F-Hyp VHL ligands 14a,b as suitable cellular probes and motivated us to pursue incorporation into VHL-targeting molecular degraders.

2.5. F-Hyp-Containing PROTACs: Effect of Fluorination on Targeted Protein Degradation. PROTACs are bivalent degrader molecules composed of a moiety that binds an E3 ubiquitin ligase (such as VHL) linked to another moiety that binds a target protein, such that the E3 and the target protein are brought into close spatial proximity. This triggers the polyubiquitylation and subsequent proteasomal degradation of the target protein, enabling post-translational elimination of a specific gene product inside the cell (Figure 1A).

Our crystal structure of the VHL:MZ1:Brd4 ternary complex and supporting biophysical studies have demonstrated that productive assembly of the ternary complex ligase:PROTAC:target depends on the de novo formation of PROTACmediated protein-protein interactions (PPIs) between the target protein and the ligase. ${ }^{45,52}$ These induced interactions in the ternary complex can result in preferential recognition of a given target protein even against members of highly conserved protein families, in spite of using nonselective target ligands. For instance, we have shown that a pan-selective inhibitor of the BET protein family, JQ1, can be derivatized using the VHL ligand VH032 to obtain a PROTAC (MZ1, Figure 1C) that is a preferential degrader for a single member of the BET family, Brd4. By changing the Hyp in PROTAC MZ1 with $(3 S, 4 S)$ and $(3 R, 4 S)$-F-Hyps we sought to generate two epimeric FHyp PROTACs (Figure 7A). These F-Hyp analogues are expected to have identical binding modes compared to MZ1, the same binary binding affinities for the target BET bromodomains, and extremely similar physicochemical proper- 


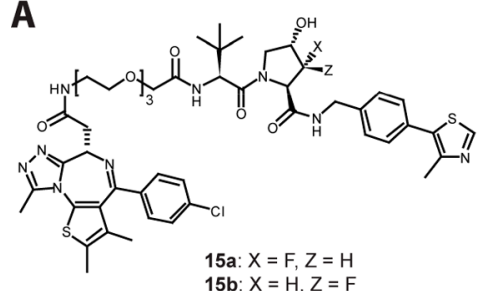

C

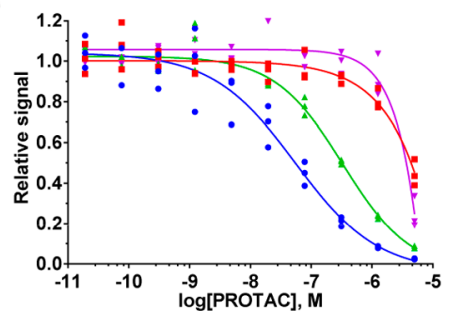

B

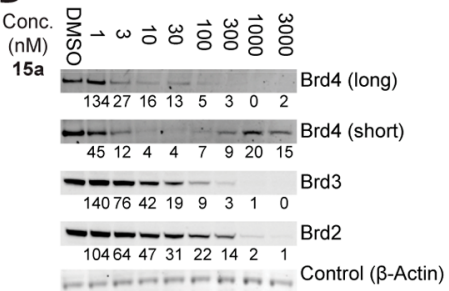

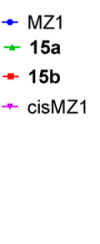

D

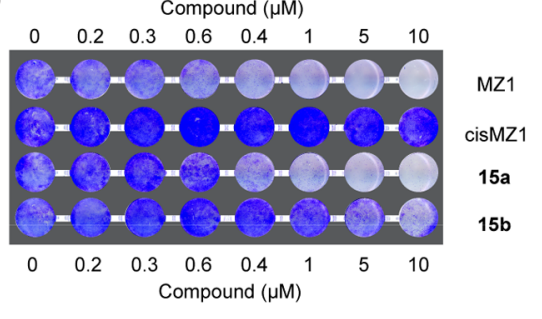

Figure 7. BET protein degradation induced by F-Hyp-containing PROTACs. (A) Chemical structure of PROTACs 15a,b. (B) HeLa cells were treated with $15 \mathrm{a}$ or $\mathbf{1 5 b}$ and vehicle control (0.01\% DMSO) for $24 \mathrm{~h}$. Abundance of individual BET protein was analyzed by Western blotting using corresponding specific antibodies after SDS-PAGE. (C) Antiproliferative activity of compounds 15a,b, MZ1, and inactive epimer cisMZ1. MV4;11 cells were treated with compounds for $72 \mathrm{~h}$ prior to quantitation of cell proliferation using the CellTiter-Glo luminescent cell viability assay. The relative signal reflects luminescence values normalized to DMSO control. (D) A549 cells stained with crystal violet dye, following a 7-day incubation with compounds 15a,b, MZ1, and inactive epimer cisMZ1. Dark background was added to improve legibility.

ties, but considerably different binary binding affinity for the VHL ligase. We therefore hypothesized that F-Hyp analogues of MZ1 could help to understand whether and how changing the binary affinity for one component of the ternary complex can impact target degradation. Moreover, fluorination of the hydroxyproline core of a PROTAC may be useful to modulate physicochemical properties of the resulting PROTAC compound. We thus prepared the F-Hyp-containing PROTAC 15a,b, analogues of MZ1 (Figure 7A), which were synthesized according to the synthetic protocol reported previously by our group. ${ }^{45,46}$ First, we measured the binary binding affinity of $\mathbf{1 5 a} \mathbf{a}, \mathbf{b}$ for $\mathrm{VBC}$ and observed that, consistently with what was found for the F-Hyps-containing peptides and VHL ligands (Table 2), PROTAC 15a, featuring the $(3 R, 4 S)$ isomer of FHyp, showed the highest binary binding affinity for VBC $\left(K_{\mathrm{d} \text { binary, } \mathrm{VBC}}=249 \pm 6 \mathrm{nM}\right.$, Supp. Table 5). PROTAC 15b was found to be a 2.5 -fold weaker ligand $\left(K_{\mathrm{d}}\right.$ binary,VBC $=603 \pm 74$ $\mathrm{nM}$, Supp. Table 5). In previous work ${ }^{52}$ we have shown that MZ1 binds VHL and the bromodomain target proteins in a cooperative fashion, $\left(K_{\mathrm{d} \text { binary, } \mathrm{VBC}} / K_{\mathrm{d} \text { ternary }}=\alpha>1\right)$ as a result of favorable PROTAC-induced PPIs. Cooperative binding was found also for F-Hyp-containing PROTACs 15a,b, with $\alpha$ values of the system VHL:15a,b:Brd4 ( $\alpha=9.5$ for 15a and $\alpha=$ 14.5 for $\mathbf{1 5 b}$, Supp. Table 5 ) in line with the values previously measured for MZ1 $\left(\alpha=9.5-17.6^{45,52}\right)$. Together these data are consistent with fluorination of Hyp maintaining the cooperative recognition and relative binding mode of MZ1 within the ternary complex.

Encouraged by the biophysical validation, we next investigated to what extent F-Hyp-containing PROTACs could induce degradation of target proteins $\mathrm{Brd} 2, \mathrm{Brd} 3$, and Brd4 in cells. PROTAC 15a was able to induce potent degradation of Brd4 (both short and long isoforms) with a $\mathrm{DC}_{50}$ between 1 and $3 \mathrm{nM}$ (Figure 7B). In contrast, degradation of $\mathrm{Brd} 2$ and $\mathrm{Brd} 3$ occurred only at higher concentrations $\left(\mathrm{DC}_{50} \approx 10 \mathrm{nM}\right)$, consistent with the preferential Brd4 degradation documented with MZ1 degrader. ${ }^{46,52}$ Compound $\mathbf{1 5 b}$ showed a reduced potency in terms of $\mathrm{Brd} 4$ degradation, with a $\mathrm{DC}_{50}$ between 10 and 30 $\mathrm{nM}$. Crucially, however, degradation of cellular Brd2 and Brd3 could be observed only at the highest concentration of $\mathbf{1 5 b}$ tested $\left(\mathrm{DC}_{50} \approx 3 \mu \mathrm{M}\right.$, Figure $\left.7 \mathrm{~B}\right)$. To evaluate the impact of $\mathrm{BET}$ protein degradation on the antiproliferative activity of BET-sensitive cancer cell lines, compounds $\mathbf{1 5 a} \mathbf{a}, \mathbf{b}$ were tested first in acute myeloid leukemia MV4;11 cells (Figure 7C) and compared with MZ1 and the inactive epimer cisMZ1. ${ }^{45,46}$ PROTAC 15a showed a marked antiproliferative effect $\left(\mathrm{pEC}_{50}\right.$ = 6.5), albeit weaker than MZ1 $\left(\mathrm{pEC}_{50}=7.3\right)$, with similar maximal response at the highest concentration used when compared to $\mathrm{MZ1}$ ( $E_{\max }=92 \%$ and $98 \%$, respectively). In contrast, PROTAC $\mathbf{1 5 b}$ showed a much weaker antiproliferative effect compared to MZ1 or 15a, and incomplete maximal response to baseline level was observed even at the highest concentration tested. A similar trend was observed in a colonyformation assay using BET-sensitive lung adenocarcinoma A549 cells treated with test compounds for 7 days (Figure 7D). In this assay, treatment with PROTACs 15a and MZ1 resulted in profound concentration-dependent cytotoxicity, whereas $\mathbf{1 5 b}$ affected cell growth only modestly even at the highest concentration tested. Taken together, the data support more potent degradation activity for degraders that incorporate the $(3 R, 4 S)$-F-Hyp epimer, which is preferentially recognized by VHL. The markedly more profound growth inhibition activity observed between the two BET degraders investigated here is contributed at least in part by these differences in E3 ligase-binding affinities. At the same time, the data provide also strong evidence that pan-selective degradation of all three BET proteins Brd2, Brd3, and Brd4 leads to a much more profound antiproliferative impact in these cancer cell lines compared to selective Brd4 degradation, as was recently observed in other cancer cell lines too. ${ }^{68}$ Crucially nevertheless, we show that losing over 20 -fold binding affinity at one of the two binding ends of a PROTAC still leads to effective degradation of the 
target protein at concentrations $\sim 100$-fold lower than the binding $K_{\mathrm{d}}$ of the warhead ligand.

\section{CONCLUSION}

We devise a simple, efficient, and scalable synthetic protocol for the preparation of all four diastereoisomers of F-Hyps starting from readily available $\mathrm{N}$-Boc-4-oxo-L-proline benzyl ester. Stereoselective fluorination of the proline ring is demonstrated when starting from $N$-phenylfluorenyl-protected 4-oxo-L-proline methyl ester. By means of computational studies on model compounds and small-molecule X-ray crystallography we have delineated the effect of fluorination on the conformational preferences and $\mathrm{H}$-bond donor capacity of the Hyp core. Hydroxyproline has a crucial role in structural proteins, e.g., collagen and elastin, and cell signaling pathways such as hypoxic response. Conformational control in proline systems is thus a subject of intense investigation, with important biological and technical applications. Our discovery that fluorination of Hyp inverts the natural preference from the $\mathrm{C}^{4}$-exo pucker to the $\mathrm{C}^{4}$-endo pucker could have unforeseen applications in protein engineering, e.g., enabling design of new molecular switches based on F-Hyps.

Hydroxyproline-containing VHL-hijacking PROTACs are being considered as clinical candidates. Because the hydroxyproline moiety is absolutely critical for molecular recognition, all VHL ligands known to date contain the natural amino acid. The discovery that VHL can also recognize stereoselectively the $(3 R, 4 S)$ epimer of F-Hyp represents an important step forward by expanding the chemical space of chemical degraders. Incorporation of the weak-affinity $(3 S, 4 S)$ epimer of F-Hyp induced target-selective degradation at concentrations over 2 orders of magnitude lower than the binary $K_{\mathrm{d}}$ for VHL. This realization has important implications for drug design of degraders where only weak-affinity binding ligands may be available, for example, against poorly ligandable targets. It is expected that the structure-activity relationships extensively delineated for Hyp-containing VHL ligands ${ }^{38-40}$ should directly translate upon F-Hyp replacement, thereby allowing expansion of chemical space while fine-tuning molecular and pharmacokinetic properties of VHL inhibitors and VHL-targeting PROTACs. The structural, binding, and cellular PK characterization of F-Hyps and proof-of-concept application as chemical tools disclosed in this work together qualify F-Hyps as useful building blocks for incorporation in future small molecules of medicinal relevance and to probe cell biology. They also provide a blueprint to pursue other fluorohydrin-containing molecules that could inspire new applications to small-molecule discovery.

\section{ASSOCIATED CONTENT}

\section{(S) Supporting Information}

The Supporting Information is available free of charge on the ACS Publications website at DOI: 10.1021/jacs.8b05807.

Supplementary results (Tables S1-S6 and Figures S1S5); materials and methods section; supplementary references; crystal structures have been deposited in the PDB with accession codes 6GFX, 6GFY, and 6GFZ for VBC in complex with compounds 13a, 14a, and 14b, respectively; data collection and refinement statistics; representative ITC titrations; NMR spectra of key intermediates and final compounds (PDF) Crystal structures of compound $\mathbf{4 a}$ (CIF)
Crystal structure of compound $\mathbf{4 b}$ (CIF)

Crystal structure of compound $4 \mathrm{c}$ (CIF)

Crystal structure of compound 10 (CIF)

\section{AUTHOR INFORMATION}

\section{Corresponding Author}

*a.ciulli@dundee.ac.uk

ORCID $\odot$

Andrea Testa: 0000-0002-8973-9711

Xavier Lucas: 0000-0003-0887-3976

Alessio Ciulli: 0000-0002-8654-1670

\section{Present Address}

${ }^{\perp}$ M.S.G.: Division of Biomedical and Life Sciences, Faculty of Health and Medicine, Lancaster University, Lancaster LA1 4YQ U.K.

\section{Notes}

The authors declare no competing financial interest.

\section{ACKNOWLEDGMENTS}

This project has received funding from the European Research Council (ERC) under the European Union's Seventh Framework Programme (FP7/2007-2013) as a Starting Grant to A.C. (grant agreement no. ERC-2012-StG-311460 DrugE3CRLs). X.L. and K.-H.C. were supported by Marie Skłodowska-Curie Actions Individual Fellowships from the European Commission (H2020-MSCA-IF-2015-806323 and H2020-MSCA-IF-2014-655516, respectively). G.V.C. was supported by a Ph.D. Studentship from the Coordenação de Aperfeiçoamento de Pessoal de Nivel Superior (CAPES, No. 7148-14-3). A.C.R. was supported by a BBSRC EASTBIO Doctoral Training Partnership award (BB/J01446X/1). Biophysics and drug discovery activities were supported by Wellcome Trust strategic awards to Dundee (100476/Z/12/Z and $094090 / \mathrm{Z} / 10 / \mathrm{Z}$, respectively). We thank Kevin Read and the DMPK team of the Dundee Drug Discovery Unit for cellular PK data, Professor B. Linclau for helpful discussions, P. Fyfe for support with in-house X-ray facilities, and the Diamond Light Source for beamtime (BAG proposals MX10071 and MX14980) and beamline support at beamlines I03, I04, and I04-1.

\section{REFERENCES}

(1) Gorres, K. L.; Raines, R. T. Crit. Rev. Biochem. Mol. Biol. 2010, $45,106$.

(2) Walsh, C. T.; Garneau-Tsodikova, S.; Gatto, G. J., Jr. Angew. Chem., Int. Ed. 2005, 44, 7342.

(3) Loenarz, C.; Coleman, M. L.; Boleininger, A.; Schierwater, B.; Holland, P. W.; Ratcliffe, P. J.; Schofield, C. J. EMBO Rep. 2011, 12, 63.

(4) DeRider, M. L.; Wilkens, S. J.; Waddell, M. J.; Bretscher, L. E.; Weinhold, F.; Raines, R. T.; Markley, J. L. J. Am. Chem. Soc. 2002, 124, 2497.

(5) Bretscher, L. E.; Jenkins, C. L.; Taylor, K. M.; DeRider, M. L.; Raines, R. T. J. Am. Chem. Soc. 2001, 123, 777.

(6) Hodges, J. A.; Raines, R. T. J. Am. Chem. Soc. 2005, 127, 15923.

(7) Wolfe, S. Acc. Chem. Res. 1972, 5, 102.

(8) Loenarz, C.; Mecinovic, J.; Chowdhury, R.; McNeill, L. A.; Flashman, E.; Schofield, C. J. Angew. Chem., Int. Ed. 2009, 48, 1784.

(9) Shoulders, M. D.; Kotch, F. W.; Choudhary, A.; Guzei, I. A.; Raines, R. T. J. Am. Chem. Soc. 2010, 132, 10857.

(10) Jenkins, C. L.; Bretscher, L. E.; Guzei, I. A.; Raines, R. T. J. Am. Chem. Soc. 2003, 125, 6422. 
(11) Taylor, C. M.; Hardré, R.; Edwards, P. J. B. J. Org. Chem. 2005, 70, 1306.

(12) Pandey, A. K.; Naduthambi, D.; Thomas, K. M.; Zondlo, N. J. J. Am. Chem. Soc. 2013, 135, 4333.

(13) Kim, W.; Hardcastle, K. I.; Conticello, V. P. Angew. Chem., Int. Ed. 2006, 45, 8141 .

(14) Newberry, R. W.; Raines, R. T. In Peptidomimetics I; Lubell, W. D., Ed.; Springer International Publishing: Cham, 2017; p 1.

(15) Kubyshkin, V.; Afonin, S.; Kara, S.; Budisa, N.; Mykhailiuk, P. K.; Ulrich, A. S. Org. Biomol. Chem. 2015, 13, 3171.

(16) Nishi, Y.; Uchiyama, S.; Doi, M.; Nishiuchi, Y.; Nakazawa, T.; Ohkubo, T.; Kobayashi, Y. Biochemistry 2005, 44, 6034.

(17) Crespo, M. D.; Rubini, M. PLoS One 2011, 6, e19425.

(18) Steiner, T.; Hess, P.; Bae, J. H.; Wiltschi, B.; Moroder, L.; Budisa, N. PLoS One 2008, 3, e1680.

(19) Thomas, C. A.; Talaty, E. R.; Bann, J. G. Chem. Commun. 2009, 3366.

(20) Skovgaard, D.; Kjaer, A.; Heinemeier, K. M.; Brandt-Larsen, M.; Madsen, J.; Kjaer, M. PLoS One 2011, 6, e16678.

(21) Meanwell, N. A. J. Med. Chem. 2018, DOI: 10.1021/ acs.jmedchem.7b01788.

(22) Chia, P. W.; Livesey, M. R.; Slawin, A. M.; van Mourik, T.; Wyllie, D. J.; O’Hagan, D. Chem. - Eur. J. 2012, 18, 8813.

(23) Gillis, E. P.; Eastman, K. J.; Hill, M. D.; Donnelly, D. J.; Meanwell, N. A. J. Med. Chem. 2015, 58, 8315.

(24) O’Hagan, D. Future Med. Chem. 2011, 3, 189.

(25) Purser, S.; Moore, P. R.; Swallow, S.; Gouverneur, V. Chem. Soc. Rev. 2008, 37, 320.

(26) Jansen, K.; Heirbaut, L.; Verkerk, R.; Cheng, J. D.; Joossens, J.; Cos, P.; Maes, L.; Lambeir, A. M.; De Meester, I.; Augustyns, K.; Van der Veken, P. J. Med. Chem. 2014, 57, 3053.

(27) Staas, D. D.; Savage, K. L.; Sherman, V. L.; Shimp, H. L.; Lyle, T. A.; Tran, L. O.; Wiscount, C. M.; McMasters, D. R.; Sanderson, P. E.; Williams, P. D.; Lucas, B. J., Jr.; Krueger, J. A.; Lewis, S. D.; White, R. B.; Yu, S.; Wong, B. K.; Kochansky, C. J.; Anari, M. R.; Yan, Y.; Vacca, J. P. Bioorg. Med. Chem. 2006, 14, 6900.

(28) Somovilla, V. J.; Bermejo, I. A.; Albuquerque, I. S.; MartínezSáez, N.; Castro-López, J.; García-Martín, F.; Compañón, I.; Hinou, H.; Nishimura, S.-I.; Jiménez-Barbero, J.; Asensio, J. L.; Avenoza, A.; Busto, J. H.; Hurtado-Guerrero, R.; Peregrina, J. M.; Bernardes, G. J. L.; Corzana, F. J. Am. Chem. Soc. 2017, 139, 18255.

(29) Mullard, A. Nat. Rev. Drug Discovery 2018, 17, 81.

(30) Graton, J.; Wang, Z.; Brossard, A. M.; Monteiro, D. G.; Le Questel, J. Y.; Linclau, B. Angew. Chem., Int. Ed. 2012, 51, 6176.

(31) Schofield, C. J.; Ratcliffe, P. J. Nat. Rev. Mol. Cell Biol. 2004, 5, 343.

(32) Hon, W. C.; Wilson, M. I.; Harlos, K.; Claridge, T. D.; Schofield, C. J.; Pugh, C. W.; Maxwell, P. H.; Ratcliffe, P. J.; Stuart, D. I.; Jones, E. Y. Nature 2002, 417, 975.

(33) Min, J. H.; Yang, H.; Ivan, M.; Gertler, F.; Kaelin, W. G., Jr.; Pavletich, N. P. Science 2002, 296, 1886.

(34) Kamura, T.; Koepp, D. M.; Conrad, M. N.; Skowyra, D.; Moreland, R. J.; Iliopoulos, O.; Lane, W. S.; Kaelin, W. G., Jr.; Elledge, S. J.; Conaway, R. C.; Harper, J. W.; Conaway, J. W. Science 1999, $284,657$.

(35) Stebbins, C. E.; Kaelin, W. G., Jr.; Pavletich, N. P. Science 1999, $284,455$.

(36) Maxwell, P. H.; Wiesener, M. S.; Chang, G. W.; Clifford, S. C.; Vaux, E. C.; Cockman, M. E.; Wykoff, C. C.; Pugh, C. W.; Maher, E. R.; Ratcliffe, P. J. Nature 1999, 399, 271.

(37) Van Molle, I.; Thomann, A.; Buckley, D. L.; So, E. C.; Lang, S.; Crews, C. M.; Ciulli, A. Chem. Biol. 2012, 19, 1300.

(38) Soares, P.; Gadd, M. S.; Frost, J.; Galdeano, C.; Ellis, L.; Epemolu, O.; Rocha, S.; Read, K. D.; Ciulli, A. J. Med. Chem. 2018, $61,599$.

(39) Galdeano, C.; Gadd, M. S.; Soares, P.; Scaffidi, S.; Van Molle, I.; Birced, I.; Hewitt, S.; Dias, D. M.; Ciulli, A. J. Med. Chem. 2014, 57, 8657.
(40) Frost, J.; Galdeano, C.; Soares, P.; Gadd, M. S.; Grzes, K. M.; Ellis, L.; Epemolu, O.; Shimamura, S.; Bantscheff, M.; Grandi, P.; Read, K. D.; Cantrell, D. A.; Rocha, S.; Ciulli, A. Nat. Commun. 2016, 7, 13312 .

(41) Buckley, D. L.; Van Molle, I.; Gareiss, P. C.; Tae, H. S.; Michel, J.; Noblin, D. J.; Jorgensen, W. L.; Ciulli, A.; Crews, C. M. J. Am. Chem. Soc. 2012, 134, 4465.

(42) Bondeson, D. P.; Crews, C. M. Annu. Rev. Pharmacol. Toxicol. 2017, 57, 107.

(43) Buckley, D. L.; Crews, C. M. Angew. Chem., Int. Ed. 2014, 53, 2312.

(44) Toure, M.; Crews, C. M. Angew. Chem., Int. Ed. 2016, 55, 1966.

(45) Chan, K. H.; Zengerle, M.; Testa, A.; Ciulli, A. J. Med. Chem. 2018, 61, 504.

(46) Zengerle, M.; Chan, K. H.; Ciulli, A. ACS Chem. Biol. 2015, 10, 1770.

(47) Bondeson, D. P.; Mares, A.; Smith, I. E. D.; Ko, E.; Campos, S.; Miah, A. H.; Mulholland, K. E.; Routly, N.; Buckley, D. L.; Gustafson, J. L.; Zinn, N.; Grandi, P.; Shimamura, S.; Bergamini, G.; FaelthSavitski, M.; Bantscheff, M.; Cox, C.; Gordon, D. A.; Willard, R. R.; Flanagan, J. J.; Casillas, L. N.; Votta, B. J.; den Besten, W.; Famm, K.; Kruidenier, L.; Carter, P. S.; Harling, J. D.; Churcher, I.; Crews, C. M. Nat. Chem. Biol. 2015, 11, 611.

(48) Lai, A. C.; Toure, M.; Hellerschmied, D.; Salami, J.; JaimeFigueroa, S.; Ko, E.; Hines, J.; Crews, C. M. Angew. Chem., Int. Ed. 2016, 55, 807.

(49) Maniaci, C.; Hughes, S. J.; Testa, A.; Chen, W.; Lamont, D. J.; Rocha, S.; Alessi, D. R.; Romeo, R.; Ciulli, A. Nat. Commun. 2017, 8, 830.

(50) Crew, A. P.; Raina, K.; Dong, H. Q.; Qian, Y. M.; Wang, J.; Vigil, D.; Serebrenik, Y. V.; Hamman, B. D.; Morgan, A.; Ferraro, C.; Siu, K.; Neklesa, T. K.; Winkler, J. D.; Coleman, K. G.; Crews, C. M. J. Med. Chem. 2018, 61, 583.

(51) Gechijian, L. N.; Buckley, D. L.; Lawlor, M. A.; Reyes, J. M.; Paulk, J.; Ott, C. J.; Winter, G. E.; Erb, M. A.; Scott, T. G.; Xu, M.; Seo, H. S.; Dhe-Paganon, S.; Kwiatkowski, N. P.; Perry, J. A.; Qi, J.; Gray, N. S.; Bradner, J. E. Nat. Chem. Biol. 2018, 14, 405.

(52) Gadd, M. S.; Testa, A.; Lucas, X.; Chan, K. H.; Chen, W. Z.; Lamont, D. J.; Zengerle, M.; Ciulli, A. Nat. Chem. Biol. 2017, 13, 514.

(53) Hughes, S. J.; Ciulli, A. Essays Biochem. 2017, 61, 505.

(54) Barraclough, P.; Hudhomme, P.; Spray, C. A.; Young, D. W. Tetrahedron 1995, 51, 4195.

(55) Baumann, M.; Baxendale, I. R.; Martin, L. J.; Ley, S. V. Tetrahedron 2009, 65, 6611.

(56) Gómez-Vidal, J. A.; Silverman, R. B. Org. Lett. 2001, 3, 2481.

(57) Zanato, C.; Watson, S.; Bewick, G. S.; Harrison, W. T. A.; Zanda, M. Org. Biomol. Chem. 2014, 12, 9638.

(58) Gupta, S.; Schafmeister, C. E. J. Org. Chem. 2009, 74, 3652.

(59) Sharma, R.; Lubell, W. D. J. Org. Chem. 1996, 61, 202.

(60) Blanco, M.-J.; Paleo, M. R.; Penide, C.; Sardina, F. J. J. Org. Chem. 1999, 64, 8786.

(61) Kenny, P. W. J. Chem. Inf. Model. 2009, 49, 1234.

(62) Johnson, E. R.; Keinan, S.; Mori-Sánchez, P.; Contreras-García, J.; Cohen, A. J.; Yang, W. J. Am. Chem. Soc. 2010, 132, 6498.

(63) Glendening, E. D.; Badenhoop, J. K.; Reed, A. E.; Carpenter, J. E.; Bohmann, J. A.; Morales, C. M.; Landis, C. R.; Weinhold, F. NBO 6.0.; Theoretical Chemistry Institute, University of Wisconsin: Madison, 2013.

(64) Newberry, R. W.; Raines, R. T. Acc. Chem. Res. 2017, 50, 1838. (65) Soares, P.; Lucas, X.; Ciulli, A. Bioorg. Med. Chem. 2018, 26, 2992.

(66) Bogdan, E.; Compain, G.; Mtashobya, L.; Le Questel, J. Y.; Besseau, F.; Galland, N.; Linclau, B.; Graton, J. Chem. - Eur. J. 2015, 21,11462 .

(67) Giuffredi, G. T.; Gouverneur, V.; Bernet, B. Angew. Chem., Int. Ed. 2013, 52, 10524.

(68) Nabet, B.; Roberts, J. M.; Buckley, D. L.; Paulk, J.; Dastjerdi, S.; Yang, A.; Leggett, A. L.; Erb, M. A.; Lawlor, M. A.; Souza, A.; Scott, T. 
G.; Vittori, S.; Perry, J. A.; Qi, J.; Winter, G. E.; Wong, K.-K.; Gray, N.

S.; Bradner, J. E. Nat. Chem. Biol. 2018, 14, 431. 